\title{
Los correos terrestres de Cartagena de Indias en tiempos de la renta (1768-1810): Itinerarios, cartografía, un «mapa en relación topográfica», GPS y un SIG*
}

\author{
por \\ Werner Stangl ${ }^{1}$ \\ Universidad de Graz, Austria
}

Este artículo ensaya una reconstrucción de la organización espacial del correo terrestre en el ámbito de la administración principal de correos de Cartagena, instalada en 1768. Se apoya esencialmente en dos informes manuscritos, uno de José Antonio de Pando de aproximadamente 1774 y otro anónimo (probablemente de Antonio de Miranda) de 1801. Ambos documentos contienen detallada información sobre la frecuencia de las carreras, los lugares de tránsito, las distancias entre ellos y la calidad de caminos. Usando información complementaria como carreteras actuales, datos GPS y mapas de la época georreferenciados, se reconstruyen las rutas con un sistema de información geográfica (SIG) en un proceso que al mismo tiempo permite ponderar sobre las prácticas de medir y expresar distancias en ese tiempo.

Palabras Clave: rutas de correo; Cartagena; Tierra Firme; Miranda; Pando; distancias.

Cómo CitAR eSte ARTículo / CitATion: Stangl, Werner, "Los correos terrestres de Cartagena de Indias en tiempos de la renta (1768-1810): Itinerarios, cartografía, un «mapa en relación topográfica», GPS y un SIG”, Revista de Indias, LXXX/278 (Madrid, 2020): 199-250. https:// doi.org/10.3989/revindias.2020.007.

* Este trabajo ha sido financiado por el Fondo Científico de Austria (FWF), P 26379-G18. Agradezco a Christian Strassnig la facilitación de sus datos GPS, a los evaluadores sus valiosas sugerencias para mejorar el texto, así como a Amelia Almorza Hidalgo y Elizabeth Montáñez Sanabria la revisión idiomática del texto.

1 werner.stangl@gmail.com, ORCID iD: https://orcid.org/0000-0002-7871-4201 de uso y distribución Creative Commons Reconocimiento 4.0 Internacional (CC BY 4.0). 


\section{INTRODUCCIÓN}

El correo colonial en la América hispana era una institución que, como tantas otras, sufrió profundas reformas en la segunda mitad del siglo XVIII. El reemplazo del sistema de «correos mayores» ${ }^{2}$ por una renta real de correos en 1764 se enmarca en el conocido reformismo de esos años, época que también experimenta la introducción del estanco de tabaco en Nueva España, las primeras intendencias indianas y los inicios del «comercio libre». El objetivo principal de la renta era introducir comunicaciones estables y periódicas que se financiarían por los portes de particulares con tarifas fijas, para así asegurar el flujo de la correspondencia oficial. Al mismo tiempo, la mejorada comunicación entre comerciantes - los principales usuarios particulares del correoy su intercambio de vales y efectos fomentaría la economía y aumentaría el número de transacciones tanto en el comercio transatlántico como en economías regionales. Hay que subrayar que ya antes de la creación de la renta, los correos mayores y sus tenientes en un proceso de profesionalización habían introducido rutas ordinarias entre las ciudades principales y establecido cajas que rendían cuentas. Sin embargo, es dudoso juzgar al sistema remplazado simplemente como un sistema corrupto e ineficiente, sin también considerar la ambigüedad y flexibilidad típica de una institución de antiguo régimen en cumplir sus funciones en circunstancias generalmente inciertas y caóticas ${ }^{3}$. Pero lo que es cierto es que la sustitución de un particular en una función por gracia real o vía compra de oficio por una renta real abstracta, regulada por ordenanzas y aranceles, corresponde a un modelo de estado diferente, más estrechamente jerarquizado, regulado y supuestamente controlable.

El correo marítimo - uno mensual de La Coruña a La Habana y Veracruz creado en 1764, y luego en 1767 otro cada dos meses al Río de la Platasiempre ha recibido alguna atención historiográfica por su importancia para la comunicación entre la metrópoli y ultramar y para el tejido imperial administrativo en general ${ }^{4}$. Otro foco de estudios sobre el correo colonial hispanoamericano es la prefilatelia, que añade marcas y tarifas a la epistemología 5 . Los estudios de Garay y López Bernal ofrecen una buena imagen de las rutas y comunicaciones entre diversos puertos dentro de la red de los correos marítimos, pero con respecto a las rutas concretas no se interesan más allá de generalidades. Recientemente María Baudot investigó las posibilidades de

\footnotetext{
2 Sobre esta fase del correo en Indias cf. González, 2017 y López Bernal et al., 2014.

3 González, 2017.

4 Garay Unibaso, 1987-1996.

5 López Bernal, 2011.
} 
reunir los datos de los diarios de navegación de los paquebotes de correo en un sistema de información geográfica ${ }^{6}$. Para el caso del correo marítimo de Cartagena de Indias contamos con los recientes trabajos de Rocío Moreno sobre su establecimiento y funcionamiento administrativo ${ }^{7}$, quien actualmente estudia las resistencias inevitables del reformismo postal que apuntaba hacia un control más jerarquizado sobre las posesiones americanas. Como regla general se puede constatar un interés reciente en la agencia de actores ejecutivos, las fallas, los fraudes y la disfunción ${ }^{8}$.

Obviamente también el correo terrestre es un componente clave en la organización del sistema postal, pero muchos aspectos de su organización y funcionamiento no se han estudiado con la debida atención por la dominante epistemología de las comunicaciones transatlánticas. Particularmente la producción historiográfica sobre la geografía de los correos terrestres parece accidental y anticuada. Los estudios más sistemáticos sobre los orígenes del correo, de Walter Bose, se hicieron a mediados del siglo XX, y de la misma época son algunos capítulos dedicados en estudios generales sobre las historias del correo de diferentes naciones ${ }^{9}$. Además, como regla general, parecen principalmente reflejar los planes proyectistas, que más se publicaron, sin preguntarse demasiado en si o cómo se realizaron en el nivel operacional o si la situación se mantenía. El único monográfico reciente sobre un tema relacionado y con una epistemología moderna centrada en la producción de espacio es el de Sylvia Sellers-García de 2014 sobre el correo, la circulación de documentos y el concepto de distancia en Guatemala ${ }^{10}$. Sin embargo, no aborda cuestiones sobre la red de distribución o la penetración institucional del correo en diferentes partes del Imperio, y por tanto las consecuencias para el desarrollo regional. Para el antiguo oeste de Estados Unidos, Cameron Blevins ha escogido una narrativa espacial basada en oficinas postales para ejemplificar el proceso de integración espacial y penetración de instituciones públicas - y por tanto del Estado- en los capilares del sistema ${ }^{11}$. A su vez, los trabajos sobre las redes viales y los caminos ${ }^{12}$, aunque suelen

${ }^{6}$ Baudot Monroy, 2015.

7 Moreno Cabanillas, 2017a.

8 Pita, 2016. Araneda, 2017. Moreno Cabanillas, 2017b.

9 Mencionando algunas obras: Alcázar, 1920. Castro Estevés, 1938. Bose, 1951. Bose hizo varios trabajos sobre "Los origenes del correo [terrestre] ..." entre 1930 y 1960 de diferentes países, como Río de la Plata (1934), Chile (1936), Guatemala (1939), Paraguay (1940), Cuba (1941) y México (1947).

10 Sellers-García, 2014.

$11 \mathrm{http} / /$ web.stanford.edu/group/spatialhistory/cgi-bin/site/viz.php?id=435\&project_id=0

12 Serrera, 1992. Para "Colombia": Moreno de Ángel et al., 1995. 
tocar el asunto de correos, en cuanto a las rutas lógicamente no son sistemáticas porque tienen que considerar todo un espectro de prácticas de viaje y comercio, medios de transporte e infraestructuras materiales.

Este artículo se propone estudiar los documentos centrales sobre el alcance geográfico del correo y su desarrollo (informes, planes, itinerarios y mapas) para un espacio bien definido - la administración general de Cartagena de Indias-, averiguar el valor explicativo de tales documentos y valorar el grado en el que las instituciones imperiales a través del correo organizaron su presencia en la provincia. El caso es además interesante porque la cuestión de caminos y rutas de correo secundarias en esa zona (con excepción del istmo) ha recibido poca atención — no solo comparándose con el Río de la Plata, cuyos itinerarios de correo se citan arriba y abajo en muchas publicaciones, sino también en comparación con el resto del Nuevo Reino- en esta zona las vías de comunicación suelen reducirse al río Magdalena (sin lugar a dudas la arteria principal), así como de allá el canal del Dique y el camino terrestre a partir de Barranca para llegar a la urbe de Cartagena ${ }^{13}$.

El texto se divide en tres partes principales: En el primero, se discuten las fuentes de información sobre la organización espacial del correo. En el segundo se analizan las rutas, su funcionamiento y medios de transporte, así como también los espacios que carecían de servicio; y, en el tercero, se ensaya la transformación de la información existente en una cartografía postal, con incorporación de otros tipos de fuentes. Esas dos últimas partes se organizan según criterios geográficos similares, ruta por ruta. Aunque parezca «redundancia», se tomó esta decisión de forma deliberada para no mezclar la epistemología exclusivamente histórica sobre organización espacial del correo con la pregunta más interdisciplinaria de cómo poder llegar a una buena aproximación para la reconstrucción de los cursos del correo en forma de mapas, como primer paso hacia una reconstrucción sistemática de la red postal terrestre en la América colonial, con la ayuda de la infraestructura de HGIS de las Indias, un sistema de información histórico-geográfica ${ }^{14}$.

13 Serrera, 1992: 96-99 muestra tres mapas parciales de rutas del Nuevo Reino. Nótese la ausencia de representaciones de caminos en las provincias del litoral atlántico.

14 En línea: https://www.hgis-indias.net. La base de datos contiene localizaciones de unas 15000 poblaciones existentes en el siglo XVIII, datos sobre la extensión de audiencias, obispados, provincias y jurisdicciones en cada año entre 1701 y 1808 y una amplia gama de otros datos, p.e. de demografía. El sitio dispone de un aparato de documentación en https://www. hgis-indias.net/dokuwiki/doku.php y una presentación general de fuentes, métodos de localización, agregación de información calitativa tanto con respecto a lugares como territorios: https://www.hgis-indias.net/index.php/introduccion/presentacion. Además, cf. Stangl, 2015, 2017 y 2018. 


\section{ITINERARIOS, INFORMES Y LA CARTOGRAFÍA POSTAL EN LA AMÉRICA COLONIAL}

Considerando que el correo es una institución de carácter inherentemente espacial, sorprende la tardía representación en forma cartográfica. En la península ibérica, hay material cartográfico sobre la organización de correos a partir de 1721, aproximadamente en el mismo tiempo que en otras partes de Europa, con excepción de Francia, que cuenta con una tradición más larga ${ }^{15}$. Aún así, los mapas postales más importantes de la península son sólo de la segunda mitad del siglo XVIII: los mapas de Tomás López (1760), Bernardo Espinalt en 1775 y el Atlas Geográfico de Correos, Postas y Estafetas de la Península de España de Francisco de Yta y Juan Victoriano Xareño $(1789 / 90)^{16}$.

Para el hemisferio occidental, el material disponible es todavía más escaso y tardío: a mi conocimiento no hay ninguno anterior a 1774. El mapa postal de la Hispanoamérica colonial mejor conocido es de Félix de la Roza, administrador de Montevideo, elaborado en $1804{ }^{17}$. La información que podemos sacar del mapa por sí solo, sin embargo, es reducida porque faltan líneas de conexión entre las postas, dejando así algunas dudas sobre la organización de las carreras y las rutas ${ }^{18}$. En el ámbito neogranadino, el Archivo General de la Nación en Bogotá contiene algunos mapas, croquis o esbozos

15 El primer mapa postal moderno conocido es la Carte géographique des Postes qui traversent la France de Nicolas Sanson de 1632. Arbellot, 1992.

16 Hay varios estudios sobre la cartografía postal del siglo XVIII en España, particularmente Fernando Aranaz del Río, 2002-2004; Alonso y López Bernal, 2002-2010; el número especial dedicado a la cartografía postal en Academvs 9 (2005); y también López Gómez y Manso Porto, 2006.

17 Mapa que demuestra las situaciones de las Estafetas, y Postas de la parte Septrional [sic] del Río de la Plata, Subalternas de la Administración principal de Correos de Montevideo; Establecidas por Don Félix de la Roza, siendo Administrador de ella, 25 de febrero de 1804, AGI, MP-BUENOS_AIRES,253. En el museo Mitre, existe también un mapa de postas y carreras de la administración de Buenos Aires que se reproduce en algunas publicaciones del temprano siglo XX, pero es de 1870, reclamando ser facsímile de uno del siglo XVIII. El original, sin embargo, se desconoce, por lo que lo descartamos para el momento.

18 Esta falta es una muestra del problema general de separar a los mapas encontrados en algún legajo y ponerlos en una colección separada. Sí suele existir documentación sobre la proveniencia de los mapas, pero requiere de adicionales esfuerzos investigativos para localizar los documentos que los rodeaban y que pueden contener explicaciones e incluso leyenda. En el caso del mapa en cuestión, aparentemente sí existe un informe que lo acompañaba y que contiene detalles sobre las carreras individuales (AGI, Correos,16A, r.1, n.1). No aproveché investigar ese legajo en mi última estadía en Sevilla. Alguna información sobre su contenido está en Torre Revelo, 1984. 
de rutas del correo terrestre: dos de las rutas entre Santa Fe y Popayán ${ }^{19}$ y uno de las rutas de Santa Fe a Girón y Cúcuta de $1804^{20}$.

Se conoce un solo mapa impreso que representa carreras de correos indianos. Se trata del mapa de la América meridional del cosmógrafo mayor Juan de la Cruz Cano y Olmedilla, quien tenía acceso a información bastante detallada sobre las rutas del correo terrestre contenida en los documentos de José Manuel de Ayala, colección importantísima de 87 volúmenes que se encuentra en la Biblioteca Real de Madrid ${ }^{21}$. El mapa de América meridional de 1775 incluye las carreras principales de ese entonces, con algunos ramales cuyos cursos no coinciden bien con lo que comúnmente se puede leer en los itinerarios más tardíos.

En el Virreinato de Santa Fe, el mapa de Cruz Cano y Olmedilla representa la ruta Quito-Popayán-Santa Fe-Cartagena, con un ramal a Antioquia; luego la carrera a Maracaibo por Tunja, Pamplona y Mérida; y un ramal de Tunja por Vélez a San Gil. En cuanto al correo de Santa Fe a la costa, lo representa principalmente como ruta terrestre paralela al río Magdalena, perdiéndose entre Tablada y Chilloa, así como al norte de Mompox para reaparecer al norte en Zambrano. Últimamente, el mapa muestra la ruta del correo entre Cartagena y Santa Marta. Cabe decir que las rutas del correo son solo una de tantas capas de información recogidas por Cruz Cano y Olmedilla, junto con caminos reales de larga distancia en general, información etnológica, organización política, etc.

El primero de los dos documentos centrales de este estudio es un esfuerzo — bastante tardío, de 1801 - de «satisfacer a la orden de V.S. de 25 de octubre de 1794» en la que se solicitaba la confección de mapas de las rutas y estafetas de correo $^{22}$. La relación, fechada el 8 de enero de 1801 , no está

19 Tránsito de los correos desde Santafé a Popayán: AGN-C, SMP.4,REF.539ª Curso del Correo de Santafé a Popayán: AGN-C, SMP.4,REF.540a.

20 Plano de correos desde Santafé a Girón y Villa de Cúcuta: AGN-C, SMP.4,REF.99a.

21 Jiménez Carcés, 2016: 232-261. Del Mapa Geografico de America Meridional, Dispuesto y Gravado por D. Juan de la Cruz Cano y Olmedilla existen muchas copias en algunas variaciones que analiza Jiménez Carcés. Una copia fácilmente accesible es http://www.davidrumsey.com/maps5794.html.

22 Descripcion o Mapa en relazion topografica de las administraciones de correos y tavacos de el departamiento de Cartagena de Yndias, AGN-C, Correos-Bolivar 4, d. 28. Hay que aclarar que los dos informes en el archivo son de una misma letra, pero el informe sobre la renta de tabacos data de 1783, la de correos de 1801. Por esto, juzgo que se trata de una copia algo posterior, lo que también explica la falta de firmas. La atribución a Miranda se basa en que el texto es inequívoco que el autor es empleado de la administración general en Cartagena, íntimo con la documentación producida en ella; y de otros ejemplos (Guatemala y Montevideo, cf. notas 17 y 23) sabemos que suelen ser los administradores principales los que firman este 


\section{Mapa 1. Detalle del Mapa Geográfico de América Meridional de Cruz Cano y Olmedilla (1775)}

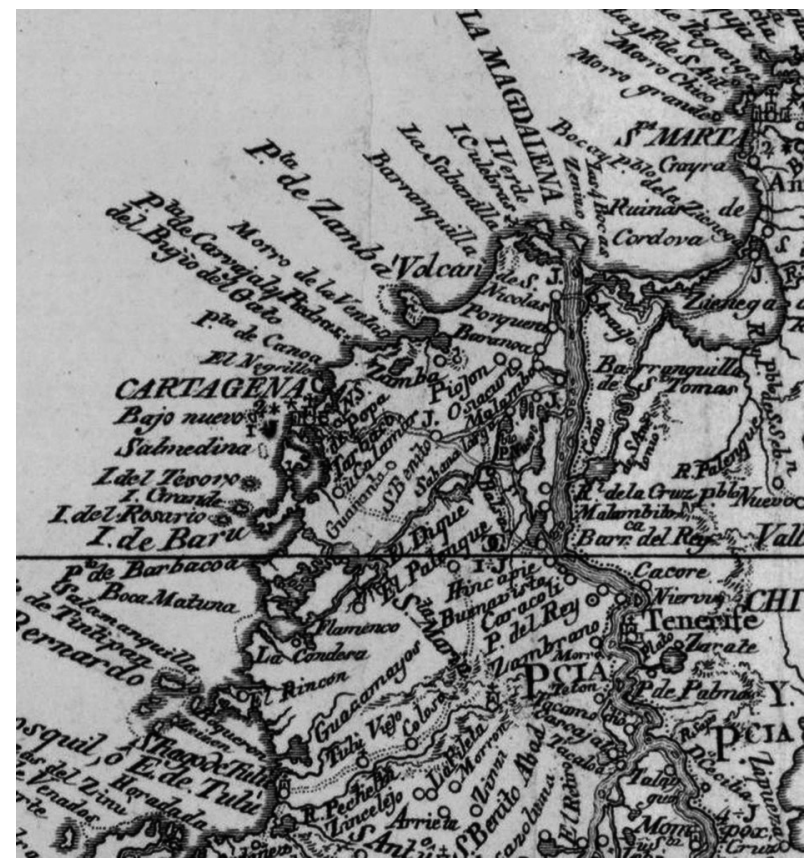

Fuente: Wikimedia-Commons. Nota: Los caminos con líneas dotadas corresponden a caminos reales, aquellos con líneas continuas a las vías principales de correo.

firmada, pero es posible suponer que su autor era el administrador principal de correos de Cartagena de Indias, Antonio de Miranda, quien ejerció ese cargo entre 1798 y 1808. Según el autor encontró dicha orden incumplida entre los papeles dejados por su antecesor y se resolvió en responderla, aunque fuese tardíamente y «en relacion por no estenderse mi inteligencia a otro genero de demostracion visual» (f.1r). Sin lugar a dudas, con esto se refiere a la confección de un mapa cartográfico.

Esta dificultad no era singular en el caso de Cartagena. Otro ejemplo de «mapa» en un formato poco común para nosotros es la carta del administrador de Guatemala, Miguel de Ateaga ${ }^{23}$, del 2 de abril de 1795. Ese «mapa» consiste en una tabla de las estafetas (administraciones menores) y postas exis-

tipo de informes generales. Por conveniencia, nos referimos al documento en lo adelante simplemente como Relación de Miranda, a pesar de la duda que queda en cuanto a la autoría.

23 Carta de Miguel de Ateaga, 2 de abril de 1795, AGI, Correos, 92B. 
tentes en su distrito, con distancias en leguas. Como Miranda, Ateaga justificó la forma de presentación del mapa postal: «La situación local de las estafetas, que no puede expresarse por carecer el Reino de mapas formales» ${ }^{24}$. Miranda, para la provincia de Cartagena, no tenía la misma excusa. Existen varios mapas de la época con una buena representación de su provincia, como el de Juan López de 1787 (mapa 2). Aun así, optó por hacer un informe textual. Aunque con este medio no logra representar las distancias de las carreras individuales tan sistemáticamente, el informe brinda una información más detallada en otros aspectos, como las alusiones a la situación económica y poblacional; o valiosos comentarios sobre cómo realmente se distribuía el correo, problemas en el transporte y particularmente la importancia de la coyuntura bélica para la organización del correo.

Adicional información sistemática sobre las carreras del correo terrestre no es precisamente abundante: En primer lugar hay un Ytinerario Real de Correos, impreso en 1778, que reúne itinerarios de diferentes carreras principales, «ramales», «comunicaciones» y «travesías» de Río de la Plata, Chile, Perú y también el virreinato neogranadino ${ }^{25}$. Aunque ha sido ocasionalmente considerado como una fuente para conocer el funcionamiento de carreras postales, su verdadero valor es difícil de averiguar.

El otro documento central para este artículo ayuda mucho en esto: se trata de un informe manuscrito de José Antonio Pando sobre las carreras de la Nueva Granada, sin datar pero escrito muy probablemente alrededor de $1774^{26}$. $\mathrm{La}$ coincidencia de los diversos itinerarios entre este manuscrito y el Itinerario Real impreso es muy alta, y sin lugar a dudas el manuscrito era la única fuente que informó al impreso sobre el correo neogranadino. La mayor diferencia está en el detalle: Mientras que el impreso solo reproduce las listas de las carreras con sus puntos de tránsito y las leguas, el manuscrito ofrece detalles sobre las etapas individuales, el terreno, el funcionamiento y frecuencia, así como proyectos

24 Ibidem, citado por Sellers-García, 2014: 211.

25 El itinerario impreso se encuentra en Reales ordenanzas, 1778: 140-166. En adelante, se refiere al itinerario como Itinerario Real.

26 «Ytinerario Real de Correo del nuevo Reino de Granada y de Tierra firme», New York Public Library, Obadiah Rich Collection, r. 60: 1r-122v. A este documento nos referimos en el presente artículo cuando mencionamos el Manuscrito de Pando. El Itinerario Real impreso, en cuanto a Nueva Granada, es derivado del manuscrito, que contiene más detalles. En cuanto a la fecha del documento, otros trabajos lo datan algo antes que nosotros. Pita, 2016: 225, incluso refiere a una aprobación por el virrey en agosto de 1770, aunque lamentablemente sin citar la fuente de esta información. En todo caso, en la descripción de la carrera entre Maracaibo y Caracas menciona una carta del 5 de febrero de 1774, por lo que por lo menos esta copia debe haberse elaborado después de esa fecha. 


\section{Mapa 2. Mapa geográfico de la provincia de Cartagena, 1787}

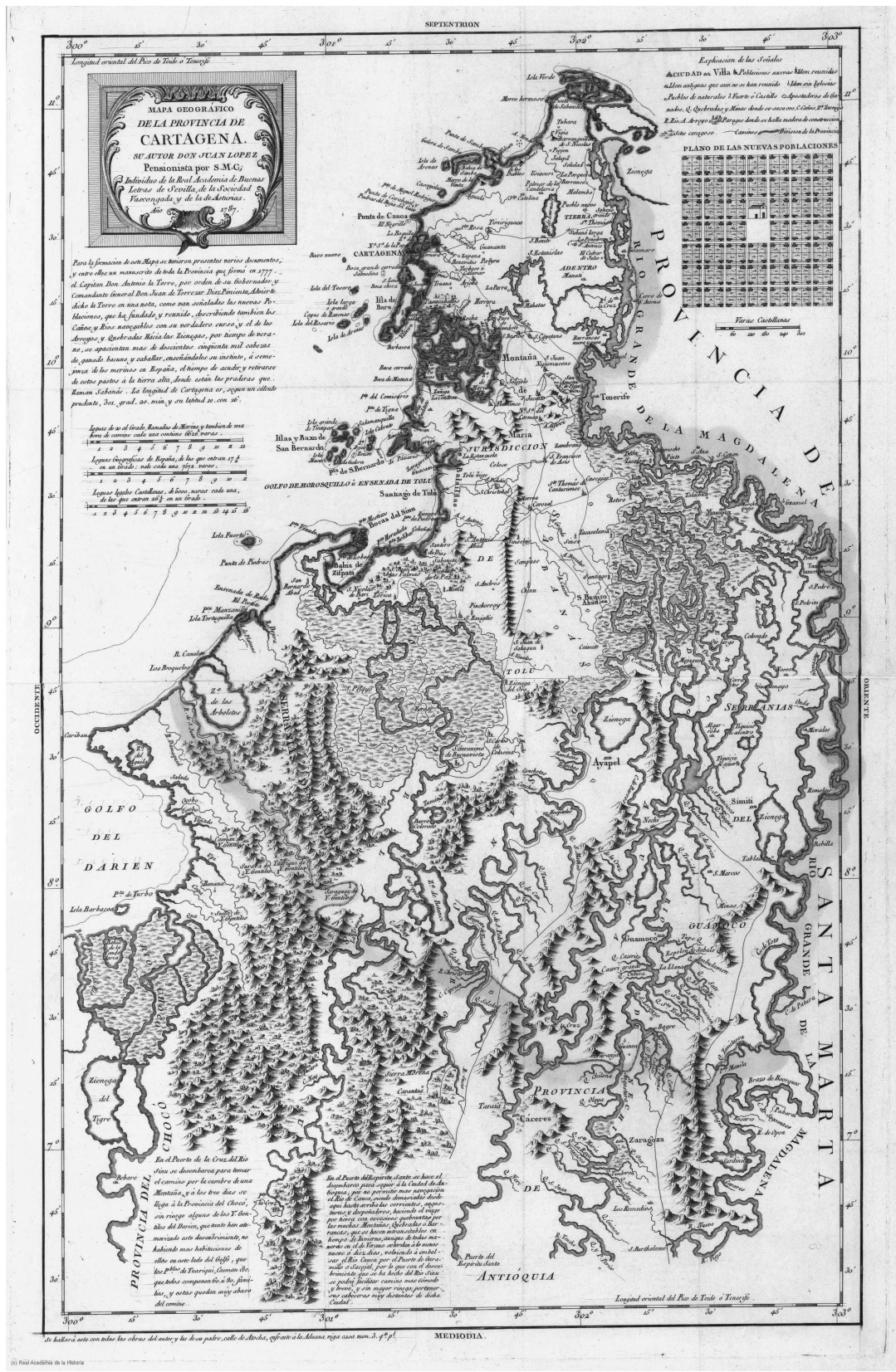

Fuente: Wikimedia-Commons.

Revista de Indias, 2020, vol. LXXX, n. ${ }^{\circ}$ 278, 199-250, ISSN: 0034-8341 https://doi.org/10.3989/revindias.2020.007 
relacionados con cada ruta, etc. Así sabemos que la mayoría de los ramales indicados no formaron parte del «correo ordinario» organizado y financiado por la renta, sino que se organizaron por las justicias de diferentes lugares y su frecuencia podía ser regular o simplemente «ofreciéndose ocasión».

Por último, existe un Estado general de todo el virreynato de Santafé de Bogotá de 1794, pero para nuestro estudio solo sirve para comparar la distribución de las estafetas porque no contiene información sobre el funcionamiento de las rutas menores dentro de la administración de Cartagena, con diferencia a las de Santa $\mathrm{Fe}^{27}$.

\section{LA GEOGRAFÍA DEl CORREO TERRESTRE DE CARTAGENA DE INDIAS}

A modo de introducción presentamos las rutas de correo contenidas en los dos manuscritos centrales de Pando y Miranda, que luego analizaremos, con indicación de si aparecen en el Itinerario Real impreso. En consideración de la proliferación de topónimos mencionados a lo largo de este artículo advierto que al final del texto se encuentran cuatro mapas que representan los poblaciones, estafetas y lugares de tránsito mencionados en el texto y uno general en el que se encuentran las provincias, regiones históricas, sierras y ríos para poder ubicarse mejor.

TABla 1. ITINERARIOS DE DiFERENTES CARRERAS POSTALES

DE LA ADMINISTRACIÓN DE CARTAGENA DE INDIAS

\begin{tabular}{|l|l|c|c|c|}
\hline \multicolumn{1}{|c|}{ De } & \multicolumn{1}{|c|}{ A } & $\begin{array}{c}\text { Distancia } \\
\text { (Manuscrito } \\
\text { de Pando })\end{array}$ & $\begin{array}{c}\text { Itinerario } \\
\text { Real }\end{array}$ & $\begin{array}{c}\text { Distancia } \\
\text { (Relación de } \\
\text { Miranda })\end{array}$ \\
\hline Santa Fe & Cartagena, por Barranca & 232 leguas & Sí & s.d. $^{28}$ \\
\hline Morales & Zimití & 8 leguas & Sí & s.d. \\
\hline Zimití & Guamocó & 25 leguas & Sí & 11 días \\
\hline Morales $^{29}$ & Ocaña & 35 leguas & Sí & 2 días \\
\hline
\end{tabular}

27 Durán, 2012: 116-122.

28 Desde Barranca hasta Cartagena indica 23 horas.

29 En Pando, la ruta va de Mompox por El Banco a Ocaña, pero en la nota que el punto de canje de la correspondencia es Morales en vez de El Banco. Las razones y consecuencias se discuten más abajo en este artículo. 


\begin{tabular}{|c|c|c|c|c|}
\hline De & $\mathbf{A}$ & $\begin{array}{c}\text { Distancia } \\
\text { (Manuscrito } \\
\text { de Pando) }\end{array}$ & $\begin{array}{c}\text { Itinerario } \\
\text { Real }\end{array}$ & $\begin{array}{c}\text { Distancia } \\
\text { (Relación de } \\
\text { Miranda) }\end{array}$ \\
\hline Mompox/El Banco ${ }^{30}$ & Valencia de Jesús & $55 / 37$ leguas & $\mathrm{Si}^{\prime 1}$ & No \\
\hline Mompox & Zaragoza & 86 leguas & No & No \\
\hline Barranca & Santa Marta & $451 / 2$ leguas & No & No \\
\hline Cartagena & Santa Marta & 60 leguas & Sí & 44 leguas \\
\hline Santa Marta & Rio del Hacha & 45 leguas & Sí & $41 / 2$ días \\
\hline Riohacha & Valledúpar & No & No & 3 días \\
\hline Cartagena & Tolú & 20 leguas & Sí & No \\
\hline Cartagena & Portobelo & 108 leguas & Sí & s.d. \\
\hline Portobelo & Panamá & 26 leguas & Sí & 26 \\
\hline Portobelo & Panamá, por Chagres & 36 leguas & No & s.d. \\
\hline Panamá & Bugava, por Veragua & 97 leguas $^{32}$ & No & 45 leguas \\
\hline Natá & Santa Liverata de las Tablas & No & No & s.d. \\
\hline Panamá & Chimán & 33 leguas & No & No \\
\hline Panamá & Antonio de Acutí & 90 leguas & No & No \\
\hline Chapigana & Tichiche & 18 leguas & No & No \\
\hline Real de Sta. María & Cana & 23 leguas & No & No \\
\hline
\end{tabular}

Fuente: Elaboración propia a partir del Manuscrito de Pando, el Itinerario Real y la Relación de Miranda . No = Ruta no incluida en la fuente; Sí = Carrera incluida en la fuente; s.d. = Distancia no indicada.

\section{LA CARRERA PRINCIPAL Y SUS RAMALES EN LA PROVINCIA DE CARTAGENA}

La ruta principal del correo entre Santafé y Cartagena es bien conocida, y no hay discrepancias fundamentales entre los dos informes de Pando y Mi-

30 Se describe dos veces en Pando: una vez solo el ramal desde el punto donde la correspondencia se aparta de la carrera principal (El Banco) y una vez inclusive Mompox, que es donde se prepara la valija de correspondencia.

31 En el itinerario impreso, hay dos rutas: A "Pueblo nuevo" (33 leguas) y "Valcencia de Jesús" (37).

3253 leguas hasta Veragua. 
randa. La ruta, recorrida dos veces al mes, entró en el ámbito de Cartagena ya por vía fluvial, siguiendo el río Magdalena hasta el sitio de Barranca, desde donde el correo se transportó por caballo. Los lugares de los dos itinerarios ofrecidos no coinciden, pero todo apunta a que no había ninguna reforma en el camino, sino que solo cambiaron los lugares considerados como importantes en el tránsito. Aun así, sorprende la diferente trayectoria del camino en el mapa de Cruz Cano y Olmedilla (mapa 2), contemporáneo a Pando. En ese mapa, el correo no cruza el dique en el sitio de Mahates sino más cercano al río Magdalena, encontrándose con el «camino de tierradentro» entre Cartagena y Santa Marta en el pueblo de San Benito.

En cuanto al servicio de correo en el sur de la provincia, la discrepancia entre Pando y Miranda es mayor. Solo coinciden en que había un correo que iba en canoa por un brazo del Magdalena desde Morales a la ciudad - poco próspera - de Simití. La continuación del correo de Simití a los minerales de Guamocó mencionada por Pando, que también se incluye en el itinerario impreso, por las tristes realidades económicas nunca realmente se realizó como servicio ordinario. Miranda todavía alude a esa ruta como idea en 1801, pero luego explica que por causa de los once días de camino despoblado y asperísimo, no se habían concretizado los proyectos, y los mineros de Simití simplemente remitieron «una $\mathrm{u}$ otra carta» con los pocos mercaderes trajinantes que frecuentaron el camino ${ }^{33}$.

Esta adhesión documental en cuanto a la posibilidad de esa ruta sorprende si la comparamos con la poca atención que recibe la comunicación de Cartagena con otra parte de su provincia: la villa de Tolú y los partidos de Sábanas de Tolú y Río Sinú. Pando menciona una travesía a Tolú, que - porque «no se halla correo establecido»- se sirvió por canoas de particulares y embarcaciones pequeñas que Pando llama «champanes», aparentemente porque le recordaron a esas embarcaciones fluviales asiáticas ${ }^{34}$. Cabe advertir que los partidos de Sábanas de Tolú y Rio Sinú así conectados con Cartagena constituían una parte importante de la provincia, tanto en extensión como demográficamente. Con Lórica y Corozal contenían dos de las poblaciones con mayor número de «vecinos blancos» (mapa 3 ).

Sorprende, por lo tanto, que la Relación de Miranda no ofrezca indicios de la falta de correo en esa parte y que en ninguno de esos lugares se estableció estafeta. La zona quedó fuera del sistema ordinario de correos hasta finales de la colonia. Es difícil encontrar una buena razón que explique por qué la renta nunca penetró en un área con estas características ni tampoco

\footnotetext{
33 Pando: 50r.

34 Pando: 58r.
} 
Mapa 3. Población de la provincia de Cartagena, 1779

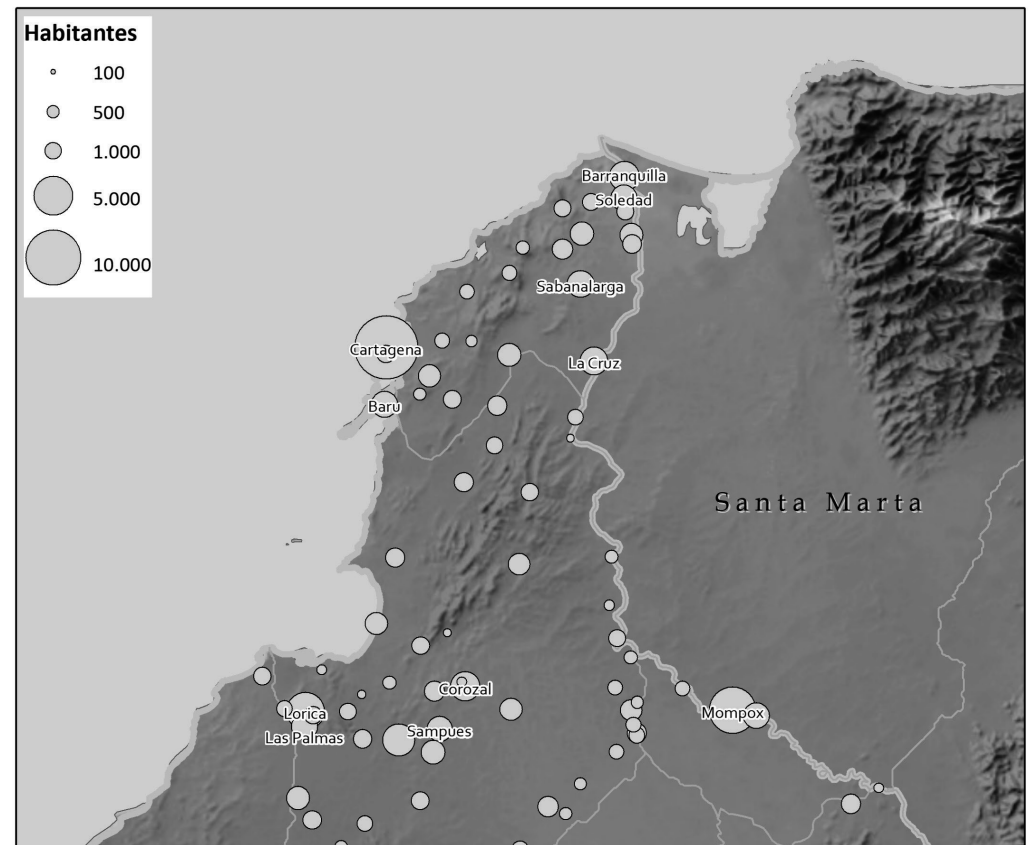

Fuente: Datos de HGIS de las Indias, que se basa en Tovar, 1994.

existían proyectos para su integración a pesar de que seguramente había mayor volumen de correspondencia que para Simití o Guamocó.

En los pantanos y la zona de los ríos de San Jorge y Cauca (parte de la jurisdicción de Mompox) tampoco existió un correo institucionalizado y organizado por la renta, pero es algo más fácil de comprender pues Pando ofrece un poco de información sobre el razonamiento administrativo. Pando describió la comunicación con esta zona en términos similares como para Tolú: Partiendo de Mompox rio abajo hasta la desembocadura del río Cauca, se hizo uso de barcos particulares que iban frecuentemente río arriba por el Cauca, pasando por los principales lugares en el área -Magangué, El Retiro y Majagual - hasta entrar en la provincia de Antioquía y terminar en Zaragoza. Pando nos informa que, ante la falta de administraciones de la renta, eran las justicias de los lugares en el camino quienes tenían que encargarse de distribuir las cartas y cobrar los portes. Además, tenían que registrar tanto las cartas pagadas como las «a sellar gratis», con un fin empírico: averiguar la rentabilidad de instalar «una barqueta de cuenta de la renta». Aparentemente, no se llegó a tal conclusión porque nunca se logró establecer un servicio 
de correo a Zaragoza, ni por el río Cauca ni por otra de las rutas indicadas por Pando por la provincia de Antioquía.

\section{Los Ramales a Ocaña y Santa Marta}

La administración de Cartagena se extendió también sobre la provincia de Santa Marta, cuyas comunicaciones se hallaron muy fragmentadas por la inaccesibilidad del centro de la provincia. En el sur estaba la ciudad de Ocaña, que tenía particular importancia para el correo porque allá la carrera principal se conectaba con la carrera importante de Santa Fe con Maracaibo y Caracas por Cúcuta. La organización inicial de este ramal no está del todo clara porque Pando ofrece dos itinerarios diferentes. Uno coincide con la ruta descrita por Miranda 25 años más tarde y se describe como un ramal ordinario, recorrido mensualmente por un conductor a pie desde Ocaña hasta el Puerto Real de las bodegas de Ocaña, donde una barqueta llevó las cartas hasta Morales, integrándose a los correos «yentes y vinientes» de la carrera principal ${ }^{35}$.

Además, Pando describe otro itinerario que comunicaba Mompox directamente con Ocaña. Según parece, en un principio se llevó toda la correspondencia de Mompox para Tamalameque y Ocaña en la carrera principal hasta el sitio de El Banco, en la banda oriental del río Magdalena. Allá se separó y se transportó a Tamalameque y Simaña en barco. En Simaña, un conductor a pie giró tierra adentro, atravesando una sierra y entrando a Ocaña por el norte, pasando por San Antonio y Río del Oro. Este itinerario, sin embargo, ya no estaba en uso en tiempos de Pando, por «algún riesgo de yndios bárbaros ${ }^{36}$. En cambio, la correspondencia de Mompox a Ocaña iba en la forma descrita por el Puerto Real, y la de Mompox a Tamalemeque simplemente se transportó en una valija aparte en la carrera principal - una forma de organización que parece más racional desde un principio considerando que Tamalameque está inmediato al río Magdalena-.

En cuanto al servicio de correos a la ciudad de Santa Marta, en un principio funcionó como un ramal de la carrera principal, a partir del sitio de Barranca del Rey ${ }^{37}$. Mejor dicho, aunque la carrera principal tenía como destino Cartagena, en sentido logístico era Cartagena el ramal: En Barranca terminó la conducción de la correspondencia de/a Cartagena por tierra y tenía

35 Pando: 49r.

36 Pando: 51v.

37 En 1765: Nota de Nicolás de Alfaro, 20 de septiembre de 1765, AGN-C, CORREOS-BOL:SC.18,2,D.20: 922r-v. 
que desembarcarse, mientras que las cartas de Santa Fe para Santa Marta continuaron por barco río abajo hasta Barranquilla y la ciénaga de Santa Marta. En tiempos de Pando, esta forma de organizarse el correo ya se había cambiado. El volumen de correspondencia entre Cartagena y Santa Marta era tal que era factible establecer dos correos mensuales directos al mes entre las ciudades, sirviendo en el tránsito también el partido de Tierradentro. Por facilidad, también la correspondencia entre Santa Marta y Santa Fe se dirigió primero a Cartagena, a pesar del camino más largo. La ruta directa según Pando ya solo se reservó para despachos oficiales extraordinarios y urgentes. Aun así, Barranca del Rey siguió siendo un importante lugar logístico en el embarque y desembarque de la correspondencia. Tanto Pando en 1774 como el Estado general para 1794 conocen una administración/estafeta de Barranca del Rey, indicando también las personas que ocuparon el cargo, los que eran a la vez capitanes a guerra del sitio $^{38}$. Aparentemente no se trató de una estafeta ordinaria porque según Miranda «[e]n Baranca, que no es lugar de correspondencia por su pequeñez y pobreza, ni vereda de travesia, ay un encargado por la renta para solo el efecto de recivir la correspondencia» ${ }^{39}$, y en el Archivo General de Indias no se encuentra ni siquiera una cuenta que diera constancia de su existencia.

Extraña también la densidad de estafetas en la carrera a Santa Marta según Pando (Sabanagrande, Sabanalarga, Soledad, Barranquilla y Ciénaga), aunque en su lista de administradores van en blanco porque «se pucieron provicionalmente en el principio del establecimiento al cuidado de las justicias ordinarias ${ }^{40}$. De esos lugares, en Ciénaga nunca se establecería una estafeta ordinaria, y en Sabanalarga solo en 1805. En cuanto al trazado del camino a Santa Marta por el partido de Tierradentro, se muestran diversas diferencias entre los documentos de Pando y Miranda. Particularmente el hecho de no mencionarse San Estanislao en el itinerario de Pando puede ser un indicativo de que el camino en 1774 todavía no tocó a ese lugar, porque sería poco común no mencionarse el lugar más importante de la zona si efectivamente la ruta pasaba por allá. Es más, también en la cartografía de la época, como el mapa de 1787 (arriba, mapa 2), y también otros de 1766 y 180541, San Estanislao queda al sur del camino. En Sabanalarga, según Pando «pueblo

38 En la década de 1770, José Santiago de Lascano: Pando: 4r; en 1793, Pablo José Torregrosa: Durán y Díaz, 2012: 124.

39 Miranda: $4 \mathrm{v}$.

40 Pando: $4 r$.

41 Mapa que comprehende parte de las Provincias de Santa Marta y Cartagena, 1766, AGI, MP-PANAMA,174. Además de las mencionadas está así también en el Mapa Topográfico de 
considerable y de comercio», empieza un pedazo de camino que definitivamente sufrió cambios. Según él, los correos desde Sabanalarga siguieron al camino real hasta Pueblo Nuevo para luego pasar a riberas del río Magdalena, a Santo Tomás y Sabanagrande «fuera del camino directo». Desde allí la ruta iba paralela al río, pasando por Malambó a Barranquilla. Esto coincide plenamente con lo que explica la Relación de Miranda sobre el itinerario. Miranda dice que al establecerse la renta, el correo había seguido esa ruta, pero que después «por la poca correspondencia» de Sabanagrande, se había evitado ese círculo ${ }^{42}$.

El panorama de alta densidad institucional contrasta fuertemente con el vacío ya referido en el sur y centro de la provincia. Pero lo que parece totalmente irracional es que la estafeta en Sabanagrande se mantuvo a pesar de la «poca correspondencia» y su exclusión de la carrera. Es más, incluso se creó toda una carrera de travesía de solo 4 leguas. Seguramente no se justificaron los gastos de un administrador y conductor asalariado, y la Relación de Miranda muestra bastante preocupación en cuanto al beneficio de los servicios para la renta de correos. Una posibilidad es que el administrador de Sabanagrande (en 1793, Félix González Polanco) ${ }^{43}$ ocupó el cargo de forma honorífica e incluso pagó el conductor a Soledad de su propio bolsillo. Cuando nos sorprendemos sobre la falta de correo en Tolú, maravilla todavía más su permanencia en Sabanagrande.

\section{LA CARRERA A RIOHACHA Y LA COMUNICACIÓN DE CARTAGENA CON MARACAIBO}

Para el camino terrestre entre Santa Marta y Riohacha, Miranda se reduce a advertir los «malos malos [sic] caminos de tierra y despoblados» ${ }^{44}$, sin indicar puntos topográficos por los que transitó el correo. Pando, en cambio, es más explícito y enumera todos los ríos que los indios conductores tenían que atravesar «vadeando con balsa [para las valijas] », y en el caso el río Enea incluso «a nado»" ${ }^{45}$. En su nota, Pando alaba los conductores indios de Mamatoco, que no solo se proveen a sí mismos con frutas, pescado y animales cazados, sino que también construyen las balsas, desprecian la idea de ir en

la Provincia de Cartagena de las Indias (1805), reproducido en Servicio histórico militar, 1980: 2, no. 29.

42 Miranda: $7 \mathrm{v}$.

43 Durán, 2012: 124.

44 Miranda: 8r.

45 Pando: 56r. 
caballo a pesar de llevar seis o más arrobas de carga, nunca tardan ni en épocas de lluvias y en caso de que uno de los dos conductores enferme, se queda solo en medio del despoblado esperando la vuelta de su colega ${ }^{46}$. El heroísmo de estos conductores es todavía mayor en la última parte del viaje donde corren riesgo de ser asaltados por los indios guajiros ${ }^{47}$. Pando relata un incidente concreto y las medidas tomadas por el comandante de Riohacha de recorrer el camino un día antes de venir el correo hasta encontrarse con él ${ }^{48}$.

Obviamente, el peligro de los guajiros era todavía mayor en el camino entre Riohacha y Maracaibo que en la costa al suroeste de Riohacha. Esta travesía tenía algún potencial para la organización del correo tanto de Cartagena como del Nuevo Reino. Como regla general, la correspondencia de Cartagena con Maracaibo y lugares de la provincia de Caracas solía transportarse en embarcaciones particulares. La correspondencia de Santa Fe iba por Tunja y Cúcuta, entrando la provincia de Maracaibo por San Cristóbal, donde aparentemente faltaron conductores tan dedicados como los de Mamatoco: El transporte era sumamente lento, particularmente entre San Cristóbal y Maracaibo (según un informe de 1761, un correo demoró en total 85 días desde Santa $\mathrm{Fe})^{49}$; había peligros de asaltos por indios motilones en el último tramo del camino antes de llegar a al lago de Maracaibo; además, no siempre había embarcación pronta para pasar la laguna, por lo que podía demorarse mucho más ${ }^{50}$. Por esto, ya en 1762 se propuso por primera vez un correo de Maracaibo por Riohacha y Valledúpar para encontrar la carrera principal en Tamalameque, pero no se realizós1.

En cuanto a la comunicación terrestre con Maracaibo por la costa atlántica, no es Miranda sino Pando el que no pierde ni una palabra. Pero es este silencio lo que tal vez nos permite datar el manuscrito con más precisión a 1774 o 1775, porque en 1775, el administrador de Maracaibo habla de un

46 Pando: 56v-57r.

47 Los indios de Mamatoco ganaron alguna prominencia también por su adhesión férrea al bando realista en las guerras de independencia: Viloria De la Hoz, 2014.

48 Pando: $56 \mathrm{v}-57 \mathrm{v}$.

49 Carta del 6 de julio de 1761, CORREOS-VEN:SC.18,1,D.3, f.258r.

50 Varias noticias en AGN-C, CORREOS-VEN:SC.18,1,D.3 y AGN-C, CORREOS-VEN:SC.18,1,D.5. Un ejemplo: Carta de Alonso del Río al virrey, Maracaibo, 6 de diciembre de 1771, AGN-C, CORREOS-VEN:SC.18,1,f. 691r; Carta de Ramón Hernández de la Calle al virrey, Maracaibo, 4 de abril de 1773, AGN-C, CORREOS-VEN:SC.18,1,D.5, f. 702r-703r.

51 José Ignacio de Michelena, Factor de la Real Compañía Guipuzcoana, envía al Excelentísimo Señor Virrey la certificación del día en que entró el correo de Santafé a Maracaibo, y su salida por la vía de Riohacha a Tamalameque, 1762, AGN-C, CORREOS-VEN:SC.18,1,D.16. 
nuevo intento de establecer un correo ordinario entre esa ciudad y Riohacha y es impensable que Pando lo desconociera ${ }^{52}$. Ese informe es positivo al respecto, diciendo que serían solo tres días de camino, salvándose entre 10 y 12 días para el giro hasta Santa $\mathrm{Fe}$, aunque también advierte «el riesgo de los yndios de la nación guagira, que no vien civilizados se esperimenta de ellos en el camino real continuas ostilidades» ${ }^{53}$. Como tantos proyectos, no se puso en práctica el correo, por lo menos hasta $1778^{54}$.

Sin embargo, en algún momento debe haberse establecido porque Miranda aclara que para 1801 el servicio entre Riohacha y Maracaibo se halló descontinuado, porque corsarios ingleses o indios guajiros podrían asaltar a los correos y apropiarse de la correspondencia ${ }^{55}$. Es más, según Miranda durante algún tiempo toda la correspondencia de Cartagena y Santa Fe con Europa pasó primero a La Guaira/Caracas y luego por tierra a Maracaibo, Riohacha y Santa Marta a Cartagena y de allá río arriba - práctica tal vez motivada por el riesgo en la mar durante la guerra-. Este riesgo se extendió desde luego a la ruta terrestre y el correo volvió a dirigirse desde La Guaira tierra adentro por la ruta tradicional por Mérida y San Cristóbal, separándose las cartas para Cartagena en Cúcuta vía Ocaña.

\section{LAS DOS VARIANTES AL VALLE DE ÚPAR}

Con respecto a la comunicación con Valledúpar, también hay una diferencia fundamental entre la Relación de Miranda y el Manuscrito de Pando, que la describen como conectada por direcciones completamente opuestas. Cabe recordar que Valledúpar era parte de la provincia de Santa Marta, pero no había camino directo a la capital porque en el centro de la provincia la Sierra Nevada y los indios de la nación chimila imposibilitaron el paso seguro. Al este, Valledúpar tenía la sierra de Perijá, otro terreno difícil, habitado por motilones hóstiles. Por lo tanto, se ofrecían dos posibles salidas: Una al nor-

52 Carta de Ramón Hernández de la Calle, Maracaibo, 14 de julio de 1775, AGN-C, CORREOS-VEN:SC.18,1,D.1: 11-13.

53 Ibidem: $12 \mathrm{v}$.

54 Hernández había, en un primer momento, establecido la ruta ya a fines de 1773 (ibidem: $28 \mathrm{v}$ ), descontinuándola luego para guardar el procedimiento y proponerla oficialmente como proyecto (ibidem: 25-26). En 1777, su sucesor volvió a sugerir tal servicio, notando que no se había puesto en práctica. No he logrado ubicar ningún documento que confirmara la realización de una carrera ordinaria por el camino real que pasó de Riohacha por Pedraza y Sinamaica a Maracaibo.

55 Miranda: $1 \mathrm{v}-2 \mathrm{v}$. 
te, por Fonseca a Riohacha; y otra al sur, por Chiriguaná al río Magdalena. La segunda variante era además la que conectaba Valledúpar con el centro del que dependió en asuntos de Real Hacienda: la villa de Mompox.

La tradicional vía de comunicación era el camino por Riohacha usado tradicionalmente por contrabandistas, y de esta forma también se representa el camino real en el mapa de Cruz Cano y Olmedilla. Pero el primer intento de establecer el correo ordinario para el Valledúpar fue por el río Magdalena, como es lógico considerando sus lazos administrativos y económicos con Mompox. Según Pando, para 1774 el administrador de El Banco en el río Magdalena separó la correspondencia para Valledúpar y la envió cada mes en canoas por el río César y por ciénagas hasta Chiriguaná, y de allá por tierra a Pueblo Nuevo y — cuatro leguas adelante- a Valencia de Jesús ${ }^{56}$. Aquí, el Manuscrito de Pando es confuso, porque ignora que «Pueblo Nuevo» y «Valencia de Jesús» son dos nombres para la misma población, lo que explica que para él ambos lugares tenían el mismo número de vecinos. Pero es muy probable que el «Valencia de Jesús» de ese documento simplemente debería ser la ciudad de Valledúpar.

Hay otra discrepancia más relevante: En el Pando, la travesía aparece como una ruta bien organizada y mensual, aunque no por cuenta de la renta sino por las justicias ordinarias «interín se nombran administradores $»^{57}$. Miranda, en cambio, aclara al respecto que «se ha querido intentar y no se ha verificado» un plan para establecer la comunicación vía Chiriguaná hacia el río Magdalena. Como razón nos ofrece la dificultad presentada por las ciénegas y los frecuentes cambios necesarios entre caminos de tierra y agua ${ }^{58}$.

Como hipótesis podría argüirse que las justicias de Valledúpar seguían costeando el envío de las correspondencias por cuenta propia durante las décadas de 1770 y 1780 porque no se estableció estafeta de la renta en esa ciudad antes de 1792. Conocemos una propuesta de 1790, que puede ser el «intento» al que se refiere Miranda, articulada por las administraciones de las rentas de tabaco y aguardientes, de establecer correo de la renta ${ }^{59}$, pero no se logró. El administrador principal de Cartagena contrapuso gastos elevados y la duración incierta del viaje y juzgó difícil encontrar personal en Chiriguaná, proponiendo la ruta alternativa por Riohacha, con un rodeo completo por

56 Pando: 49v.

57 Pando: 50r.

58 Miranda: 8v.

59 Establecimiento de correo mensual, 1790, AGN-C, Colonia, MISCELANEA:SC.39,28,D.35: 886-911. 
Santa Marta y Cartagena, para comunicar Valledúpar con Mompox ${ }^{60}$. En 1791 empezó el nuevo servicio y en 1792/1793 se establecieron las dos estafetas de Valledúpar y Barrancas ${ }^{61}$. En 1807 se erigió una estafeta también en Chiriguaná, lo que podría significar que finalmente se logró una ruta directa al río Magdalena, ya sea con o sin mantener la vereda a Riohacha, pero no he encontrado evidencia concreta al respecto.

\section{Los ITINERARIOS DE TIERRA Firme}

Tanto el Manuscrito de Pando como la Relación de Miranda contienen descripciones de las rutas del correo terrestre en Tierra Firme. En tiempos de Pando, el único itinerario que funcionó por la renta era el inevitable camino real entre Portobelo y Panamá. Ambos autores describen el camino por el istmo como uno de los peores del continente ${ }^{62}$. Para Miranda era

de asperas montañas y pasos de arroyos, rios y quebradas con hondos, obscuros cauces, mucha piedra y peñas cones haciendo mas penoso la consideracion de pasar diez y nueve veces un rio que nombran de Juan Lanas y và por entre muchas $\mathrm{y}$ grandes piedras que forman profundos socabones unos peor que otros el correo - a pie - necesitó seis, ocho o más días pasando por socavones y sufriendo lluvias y crecientes ${ }^{63}$.

Miranda menciona que por su incomodidad el camino real solo se usaba para el correo y similares despachos que «demandan igual seguridad», mientras que la mayoría de viajeros y comerciantes frecuentaron la ruta por el río Chagres y camino de Cruces. Aun así, cabe notar que las leguas del camino en la Relación de Miranda (36) son exactamente el número de la ruta por Chagres según el itinerario de Pando, mientras que el camino directo para Pando es de solo 26 leguas. También la duración de esta ruta incrementó: Mientras que, según Pando, el correo necesitó tres días y a los cinco se puso en marcha para la vuelta, para Miranda eran «seis a ocho y aún más días» y el regreso era a los nueve días - tal vez también un indicio que la ruta transístmica continuó perdiendo en importancia-. Para comparar, a principios

60 Ibidem: $889 \mathrm{v}$.

61 A partir de 1792 existen cuentas de Valledúpar, desde 1793 también de Barrancas en la sección de correos del Archivo General de Indias (AGI, Correos, 81A). El expediente sobre el establecimiento de correo mensual habla de otra estafeta en San Juan e incluso nombra el administrador, pero nunca rindió cuenta.

62 Pando: 59r-v; Miranda: 9r-v.

63 Miranda: 9v. 
del siglo XVII, un autor anónimo adscribió solo 18 leguas de distancia al camino real, con una duración de cuatro días para el viajero ordinario, ¡la mitad de lo calculado a fines de la colonia en un camino que físicamente cambió muy poco! 64

Más allá de los dos caminos ístmicos, el manuscrito de Pando contiene también itinerarios para la ruta de Panamá por Veragua hasta los confines con Costa Rica; un camino al oriente de la provincia de Panamá por Chepo hasta Chimán; y algunas cortas rutas en la provincia de Darién, que describe con un detallismo que no parece justificado En tiempo de Miranda, el Darién todavía quedó sin servicio postal por su «tenuidad y pobreza» ${ }^{65}$ y no había intento de establecerlo. Con igual derecho podría haber descrito toda una red de caminos menores en Sábanas de Tolú y Río Sinú u otras partes sin correo de la renta: Pando subraya que no existió correo establecido, y en una nota sumaria para todos estos caminos aclara que «son escasas las noticias que se tienen de estos parages por ser en la mayor parte de pueblos vagantes que sacudiendo el yugo del vazallage que tenían jurado por bolver a quedar dueños de su livertad y sin más religión que la bárbara de gentes incultas» ${ }^{66}$. El itinerario impreso por lo tanto no incluyó todas esas comunicaciones suplementarias de Tierra Firme.

A principios del siglo XIX, existían dos carreras ordinarias más en Tierra Firme: La primera seguía el camino real hasta Veragua, con un itinerario muy semejante a lo indicado ya por Pando aunque con algunas diferencias en cuanto a los lugares mencionados en el camino y en cuanto a las leguas que calculan. La diferencia principal está en la inclusión de Penonomé, lugar que sorprendentemente falta en el itinerario de Pando a pesar de ser el segundo lugar en población de toda la provincia, solo sobrepasado por la capital. Sin embargo, Penonomé está algo al norte del camino más recto entre Panamá y Veraguas, y aparentemente el itinerario solo representa el camino real. Como ya insinúa la inclusión del camino de Cruces en el Manuscrito de Pando, los itinerarios de Tierra Firme no parecen estar vinculados con el sistema de correos sino de forma más general corresponden a las vías de comunicación interprovinciales.

Una segunda diferencia es que el camino en 1801 entre Natá y Veragua ya no tocó en el pueblo de Santa María. Esta diferencia se explica fácilmente: Miranda nos informa que en Natá empezó un ramal para servir a los pueblos de la jurisdicción de Santos — otra área ignorada por Pando-. Esa ruta

\footnotetext{
64 Serrera, 1992: 79.

65 Miranda: 11r.

66 Pando: 62r.
} 
entonces tenía como primera parada al pueblo de Santa María, por lo que el correo entre Natá y Veragua podía tomar una ruta algo más directa.

Aunque faltan datos exactos sobre el establecimiento del correo a Santos, sabemos que en 1785, o poco antes, se establecieron aquellas estafetas que Miranda menciona en el camino $-\mathrm{y}$ con esto seguramente el servicio ordinario- ${ }^{67}$. La Relación de Miranda revela que algunas de las estafetas intermedias no eran rentables y que a veces los curas servían como sustitutos. Comparando las estafetas en la Relación de Miranda con aquellas cuyas cuentas se hallan en el Archivo General de Indias, se nota que en Miranda faltan varias (La Chorrera, Chame, Antón, Penonomé), que pueden ser aquellas con curas que servían como administradores. A su vez, el informe todavía menciona la estafeta en el sitio de San Carlos, mientras que la última cuenta enviada de allá data de 1800 .

La proyectada continuación del correo ordinario de Veraguas a Chiriquí y Alange no era viable sin la consecuente conexión a Costa Rica ${ }^{68}$, hacia donde solo existió un precario camino de arrieros ${ }^{69}$. Así, la correspondencia de Chiriquí se llevó por transeúntes a Veragua, donde se integró al correo ordinario. Ya como nota a pie, el servicio postal mensual entre Costa Rica y Panamá finalmente se estableció en 1811, cuando otras partes de las colonias ya se encontraron en proceso de independencia ${ }^{70}$.

\section{LA RECONSTRUCCIÓN DE LOS CAMINOS POSTALES EN UN SISTEMA DE INFORMACIÓN GEOGRÁFICA}

Para convertir la información obtenida de los informes de Pando y Miranda en una representación cartográfica nos servimos de la infraestructura HGIS de las Indias y el software ArcMap. En un primer paso, preparamos una tabla Excel de los itinerarios, averiguando el número ID de los lugares en la base de datos (gazetteer) de HGIS de las Indias, agregando también columnas para las fechas de vigencia, tal como exige el sistema (ejemplo en tabla 3; los campos en cursiva son los campos obligatorios).

${ }^{67}$ A partir de 1785, existen cuentas de esas administraciones en la sección de correos del Archivo General de Indias (AGI, Correos, 79A).

68 Miranda: $10 \mathrm{v}$.

69 Molina Montes de Oca, 2005: 216 ss.

70 Expediente sobre el proyecto promovido por el capitán general de Guatemala para que se establezca un correo terrestre entre Costa Rica y Panamá, 1809-1811, AGI, Correos, 111B, r. 2 , n. 1 . 


\section{TABla 3. ITINERARIO MOMPOX-VALLEDÚPAR}

\begin{tabular}{|l|l|c|c|c|c|c|}
\hline \multicolumn{1}{|c|}{ Desde } & \multicolumn{1}{c|}{ Lugar } & GZ_ID $_{-}$ & START $_{-}$ & $\boldsymbol{E N D}_{-}$ & Leguas & Suma \\
\hline & Mompox & 5000024 & 1768 & 1768 & & \\
\hline Mompox & El Banco & 5000399 & 1768 & 1768 & 18 & 18 \\
\hline El Banco & Chimichagua & 5000390 & 1768 & 1768 & 6 & 24 \\
\hline Chimichagua & San Vicente & 5000632 & 1768 & 1768 & 4 & 28 \\
\hline San Vicente & Chiraguana & 5000391 & 1768 & 1768 & 3 & 31 \\
\hline Chiraguana & Passo & 5000412 & 1768 & 1768 & 12 & 43 \\
\hline Passo & Pueblo nuevo & 5000411 & 1768 & 1768 & 8 & 51 \\
\hline Pueblo nuevo & $\begin{array}{l}\text { Valencia de Jesús } \\
\text { [sic; =Valledúpar] }\end{array}$ & 5000041 & 1768 & 1768 & 4 & 55 \\
\hline
\end{tabular}

Fuente: Elaboración propia, preparada para uso en HGIS de las Indias.

Los pocos lugares que no encontramos - algunos pocos buhíos y haciendas - se localizaron con servicios como OpenStreetMap. Para localizar aquellos que ni logramos identificar de esta manera, revisamos mapas históricos para por lo menos acercarnos a su ubicación histórica. Así, logramos dar coordenadas por lo menos aproximadas a cada punto de tránsito encontrado en los documentos. Después, agregamos estos lugares «nuevos» al gazetteer antes de procesar los datos con un servicio automatizado del HGIS para convertir tablas en archivos espaciales (shapefile) para posterior uso en software localizado ${ }^{71}$. Una vez obtenido el archivo, lo cargamos en el software ArcMap y conectamos los lugares con líneas rectas.

Hemos resaltado en los apartados pasados que una diferencia en los lugares de tránsito mencionados en diferentes fuentes puede, pero no tiene que significar un cambio de organización o un curso diferente. Puede ser una simple cuestión de detalle o depender de selecciones arbitrarias sobre lugares considerados importantes. Sabemos que esos puntos de referencia no siempre eran puntos de canje, casas de posta o tambos. Los itinerarios suelen incluir los lugares con mayor número de vecinos, pero en cuanto a los demás lugares

71 Para usar el servicio "upload", hay que registrarse en la página-web del proyecto y considerar que datos contribuidos estarán disponible bajo licencia Creative Commons BY-NCSA 4.0. Existen videos tutoriales en Youtube sobre cómo preparar datos y metadatos correctamente: https://youtu.be/jz5OFdvfrn4. Cada noche (MET) HGIS de las Indias convierte las tablas automáticamente en shapefiles que se pueden descargar al día siguiente. 
se desconocen las razones que decidían sobre su inclusión o exclusión de los itinerarios. No parece lógico, por ejemplo, que Pando incluye a Yucal, un pequeño pueblo de indios a una legua de Barranca, mientras que faltan pueblos y sitios de más habitantes, como Menchiquejo y Guamal, que podrían servir como puntos intermedios para estructurar las 18 leguas que median entre Mompox y El Banco - una etapa atípicamente larga.

Conectando los puntos de referencia, también se notan algunas irregularidades en los itinerarios de Pando, quien pone algunos puntos de referencia en orden inverso o poco común: en el camino de Cruces, se inviertan las haciendas de Frijoles y Palo Matías, en el camino entre Santa Marta y Riohacha las haciendas de Calabazo y Jordán, y en el itinerario de Barranca a Santa Marta pasa lo mismo con respecto a los sitios de Guaymaro y Ponedera, ubicándose Guaymaro río arriba; finalmente, en el Darién, hay un itinerario de Santa María-Yaviza-Tichichí que sería mucho más lógico recorrerse en otro orden siguiendo el curso del río que conecta los sitios. Considero que, en todos estos cuatro casos, Pando simplemente se equivocó en el orden de poner los lugares, error que suele pasar con facilidad copiando un itinerario que se había colocado en orden inverso (para ofrecer una posible razón).

Para reconstruir un curso más aproximado a las verdaderas rutas históricas que simples líneas rectas, hay varias posibilidades. Lo más sencillo son aquellas etapas de las que sabemos que seguían la vía fluvial o costera. En este caso, ignorando rectificaciones fluviales modernas, basta con seguir los cuerpos de agua. Para los caminos de tierra nos ayudan carreteras modernas, la topografía, mapas de la época que representan vías de comunicación ${ }^{72}$ y ocasionalmente también trabajos arqueológicos y de rescate del patrimonio cultural.

Otro elemento que tiene alguna capacidad de explicación — aunque no demasiado - son las distancias indicadas entre los puntos de referencia. En el manuscrito y el impreso de Pando se usa explícitamente la «legua» como medida, mientras que la Relación de Miranda usa para algunas rutas días y horas de camino. En el camino por tierra entre Cartagena y Barranca, advierte además que «haviendo muchas dudas en la distancia por leguas porque ninguna hay medida» tenía que usar horas de camino como aproximación, «juzgando una por legua». Es decir, ante la ausencia de una medida objetiva, vuelve a la primitiva definición de la legua como medida basada en la conditio humana. Comparando ambas distancias, Pando tiene 19 leguas en ese camino y Miranda calcula 24 leguas-hora para el camino, siguiendo un curso seguramente idéntico. Tampoco sería lógico suponer que Pando, un cuarto siglo antes, pudo ba-

${ }^{72}$ Las vías de comunicación en los mapas a su vez pueden ser representaciones de caminos concretos, pero también itinerarios o simplemente rutas recorridas por el cartógrafo. 
Mapa 4A. Relación Km/Legua en Cartagena SEGÚN El MANUSCRITO DE PANDO (CA 1774)

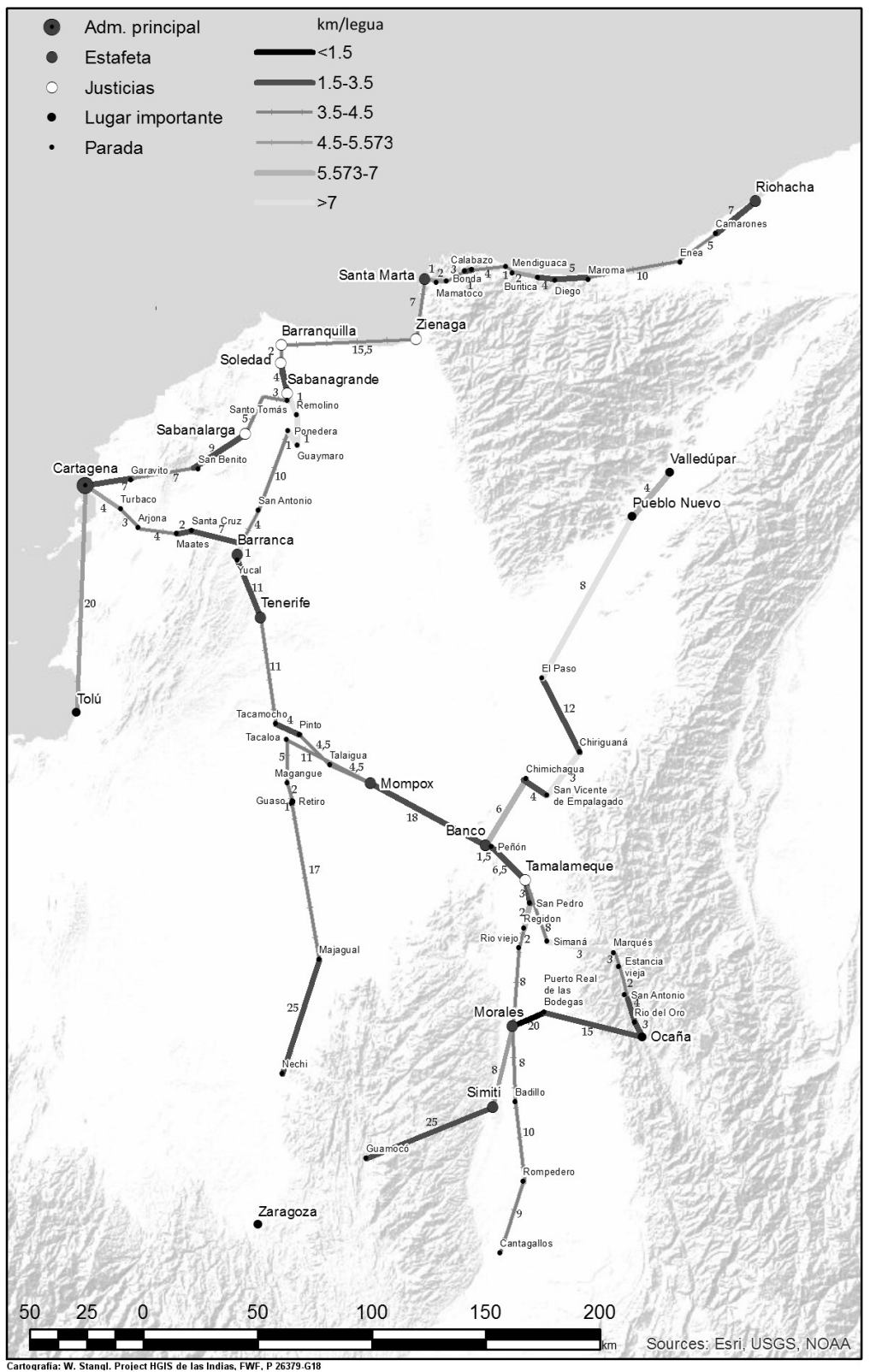

Fuente: Elaboración propia. 
Mapa 4B. Relación km/Legua en Tierra Firme SEGÚN EL MANUSCRITO DE PANDO (CA 1774)

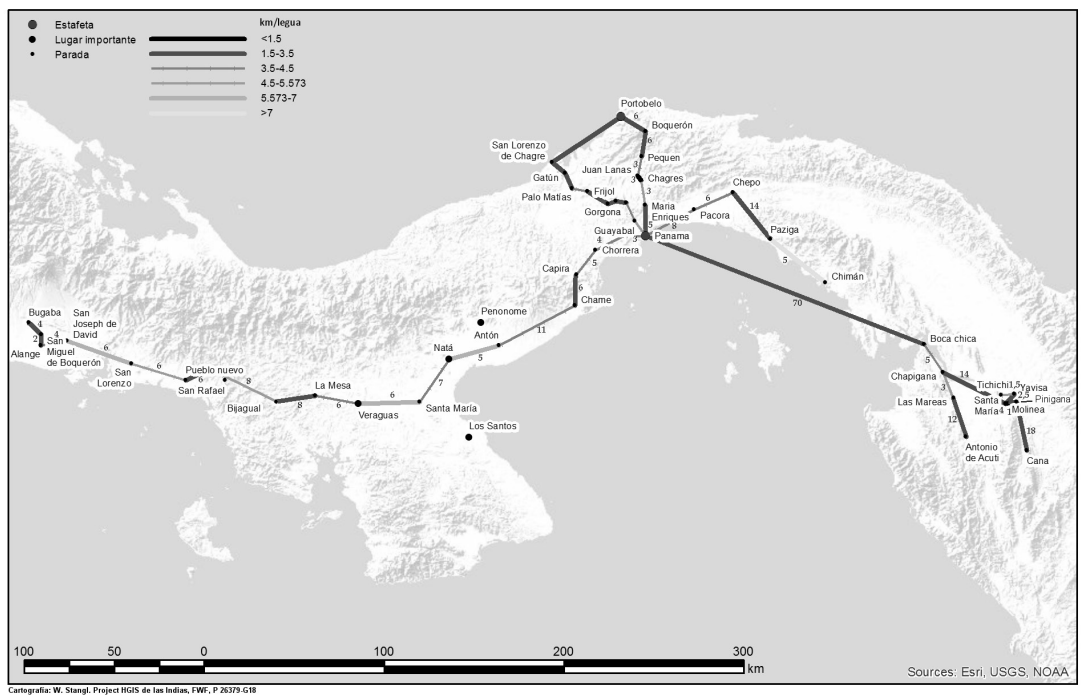

Fuente: Elaboración propia.

Mapa 5B. Relación Km/Legua en Tierra Firme SEGÚN LA RELACIÓN DE MIRANDA (1801)

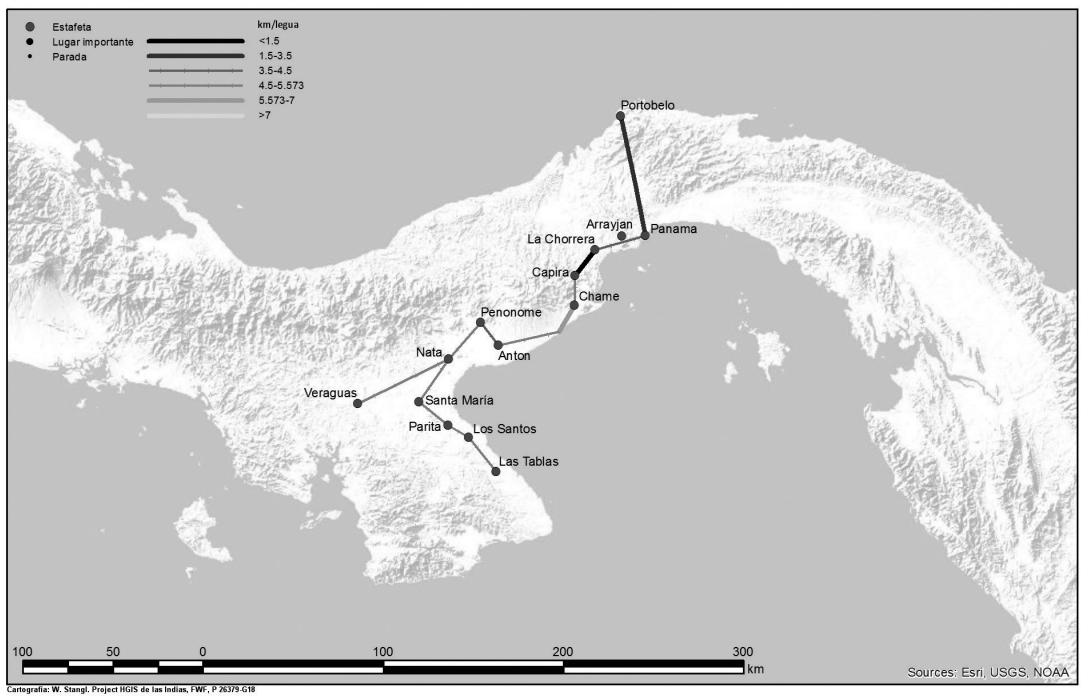

Fuente: Elaboración propia. 


\section{Mapa 5A. Relación KM/LEgua en CARTAGena SEGÚN LA RELACIÓN DE MIRANDA (1801)}

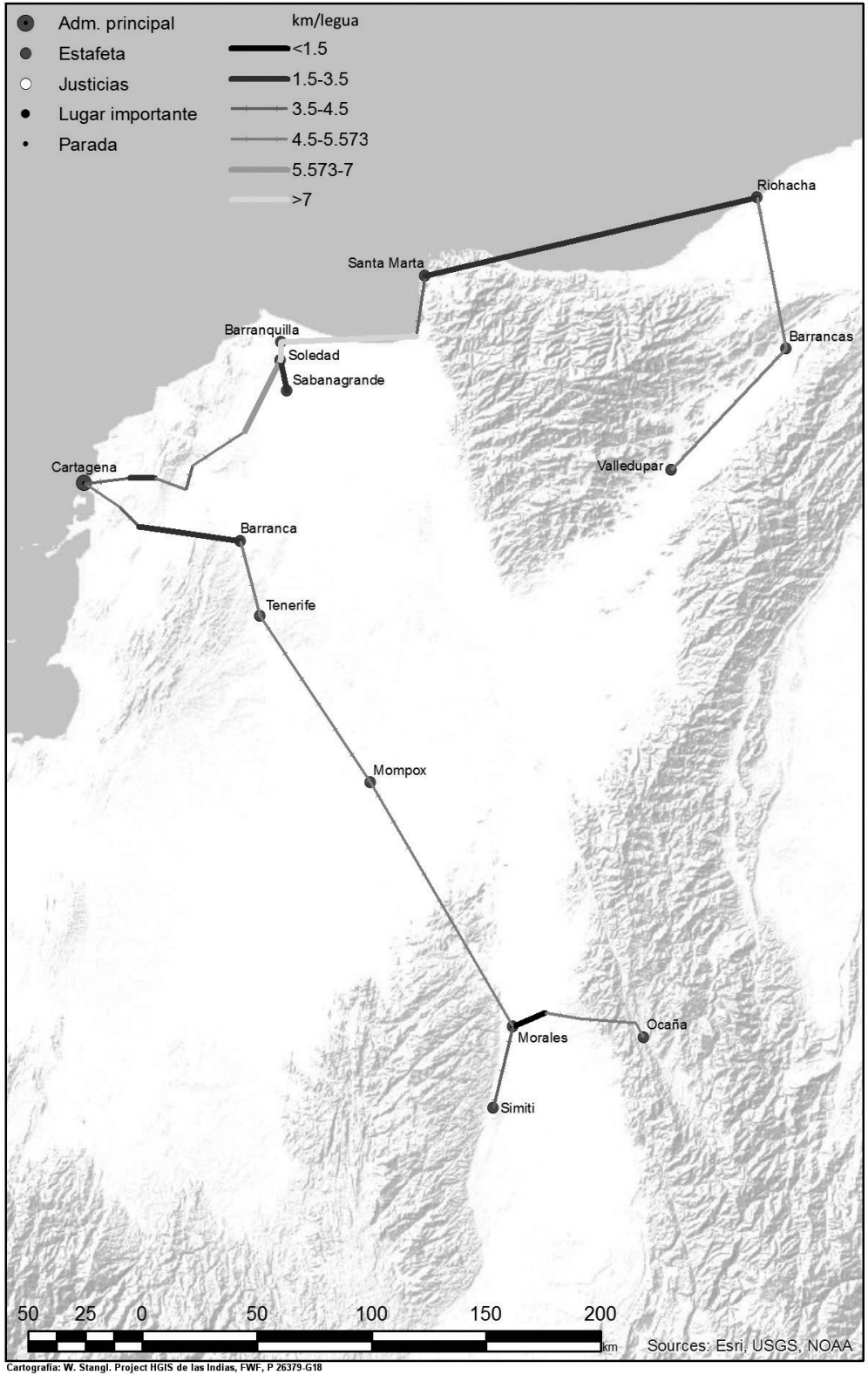

Fuente: Elaboración propia. 
sarse en un levantamiento más objetivo de medidas de distancia. Hay que estar atento al hecho de que diferentes variables entran en el cálculo de establecer las «leguas» de los itinerarios. Podemos calcular la relación entre leguas indicadas y kilómetros calculados entre los puntos de referencia.

Las líneas más oscuras nos muestran aquellos tramos con leguas muy cortas. Las líneas con segmentos interpuestos representan distancias que corresponden a leguas más o menos razonables, entre 3,5 y 5,5 km por legua. Las líneas más claras son los casos en los que la distancia en $\mathrm{km}$ por legua es mayor que la «legua de Burgos», es decir que hasta en línea recta son demasiado largas. Aunque hay diferentes explicaciones posibles para cada irregularidad, estas relaciones pueden servir de norte para cuestionar la localización inicial, si hay que buscar por un curso con desviaciones considerables, pasando por lugares en el camino que no se mencionan en el itinerario o con muchas curvas y serpentinas, por ejemplo, atravesando una serranía. En los casos de leguas extremadamente largas también hay que considerar un error manifiesto en el itinerario. Teniendo esto presente, podemos volver a las carreras anteriormente descritas para refinar la reconstrucción de la red de caminos del correo.

\section{Por el Río Magdalena y SUS TRIBUtaRios}

Para las etapas en el río Magdalena tenemos una aproximación fácil en su curso actual, aunque por supuesto en algunas ocasiones puede haber cambiado. Pero comparativamente, tenemos bastante certidumbre, lo que nos permite asesorar muy bien la distancia correspondiente a una legua fluvial. Como era de esperar, las leguas calculadas por Pando en el viaje de la carrera principal por el río Magdalena son relativamente constantes: 13 de las 16 etapas tienen leguas entre 3,8 y 5,2 km; dos de las restantes tienen relaciones más allá de los $6 \mathrm{~km}$, y la distancia entre Yucal y Barranca se da con solo una legua.

De Barranca, el correo siguió el río Magdalena para la comunicación directa con Santa Marta, pero parece cierto que las distancias de sus etapas se calcularon por otro individuo y con otro método. Para la siguiente etapa río abajo, todavía tenemos una legua más o menos regular, pero las últimas etapas son difíciles de interpretar. Primero, el orden del itinerario no es lógico, yendo primero hasta Ponedera para volver río arriba a Guaymaro para bajarlo a Remolino, y distancias por el río se regulan simplemente con una legua cada una. La comparación con las distancias reales nos da resultados entre 8,5 y 10 kilómetros, y esto ya suponiendo que Pando realmente se equivocó en el orden de las paradas y considerando que la media legua por tierra del desembarcadero a Sabanagrande simplemente no se incluyó en la legua indicada 
desde Remolino. ${ }^{73}$ Es decir, la legua en esa parte del río tiene más o menos la doble distancia de la mayoría de las leguas fluviales en la carrera principal. Pueden ser una simple conversión de horas de viaje en leguas.

Para el viaje río arriba, Pando calcula dos días de Barranca a Mompox, más once a Honda ${ }^{74}$. Según Miranda el correo llegaba desde Barranca «al tercer día» a Mompox y de allá a Morales necesitaba otros dos días. Miranda omite el resto de la ruta por estar fuera del ámbito de Cartagena ${ }^{75}$, pero sí nos informa de que la «bajada» de Santa Fe a Cartagena era de 10 días y la «subida» de 18. Esto son exactamente las cifras que ofrece el Estado general de $1794^{76}$, que además es un poco más detallado. Usando esta información y calculando con 12 horas de viaje por día ${ }^{77}$, obtenemos valores entre 10 y 16,5 $\mathrm{km} / \mathrm{h}$ en la bajada y $4-5,5 \mathrm{~km} / \mathrm{h}$ en la subida (tabla 4 ). Aunque tal vez parezca poco a primera vista, las velocidades alcanzadas en la subida no son nada despreciables si se toma en cuenta el esfuerzo necesario para la tarea. Pando describe el «abentajado trabajo» que se servían de «mosos libres fornidos» en las barquetas del correo:

El modo que usan de navegar es arrastrando la barqueta por la orilla del río con unas latas o cañas de dos y media o tres varas de largo que tienen una horquilla al remate inferior con las que haciendo fixesa en la tierra o en las ramazones o troncos de árboles y afirmando el pecho sobre la extremidad superior corren con tanta velocidad desde la punta que hace proa hasta un tercio de la popa, que se regula a dos leguas por hora en diligencia, otras veces se aprovechan de las palancas en los raudales de poca agua ${ }^{78}$.

También observamos (con alguna irregularidad en el tramo entre Nare y San Bartolomé) que la velocidad en la bajada disminuye hacia la parte baja y en la subida disminuye hacia la parte alta del río, como es lógico considerando la velocidad de los caudales.

Es por lo tanto lógico suponer que en la parte baja, donde el río correo con menor velocidad, la distancia de una legua en clave «hora de viaje» disminuya, como es el caso de las etapas desde Barranca río abajo.

73 Pando: 53v.

74 Pando: 44v.

75 Miranda: 5r-7r.

76 Durán, 2012: 115-116; Miranda: 3v-4r.

77 Es una estimación, admito, bastante arbitraria. Se basa principalmente en que las horas de días incompletas en etapas fluviales suelen tener valores de " 4 horas" u " 8 horas" si no se habla de "medio día" (cf. por ejemplo la tabla 4). Por esto me parece más lógico que el medio día no corresponda a 5 sino a 6 horas.

78 Pando: 45v-46r. 
TABla 4. Leguas POR día SEGÚN El ESTADO GENERAL

\begin{tabular}{|l|l|c|c|c|c|}
\hline \multicolumn{1}{|c|}{ De } & \multicolumn{1}{|c|}{ A } & $\begin{array}{c}\text { Leguas } \\
\text { (Pando) }\end{array}$ & $\begin{array}{c}\text { km } \\
\text { (calculados) }\end{array}$ & $\begin{array}{c}\text { Tiempo y } \\
\text { velocidad } \\
\text { «Bajada» }\end{array}$ & $\begin{array}{c}\text { Tiempo y } \\
\text { velocidad } \\
\ll \text { Subida» }\end{array}$ \\
\hline Honda & Nare & 34 & 144 & $\begin{array}{c}1 \mathrm{día} \\
(12 \mathrm{~km} / \mathrm{h})\end{array}$ & $\begin{array}{c}3 \mathrm{~d} \text { días } \\
(4 \mathrm{~km} / \mathrm{h})\end{array}$ \\
\hline Nare & S. Bartolomé & 19 & 67 & $\begin{array}{c}4 \mathrm{horas} \\
(16,75 \mathrm{~km} / \mathrm{h})\end{array}$ & $\begin{array}{c}1 \mathrm{día} \\
(5,6 \mathrm{~km} / \mathrm{h})\end{array}$ \\
\hline S. Bartolomé & Mompox & 99 & 436 & $\begin{array}{c}3 \text { días } 8 \mathrm{horas} \\
(9,9 \mathrm{~km} / \mathrm{h})\end{array}$ & $\begin{array}{c}8 \mathrm{días} \\
(4,5 \mathrm{~km} / \mathrm{h})\end{array}$ \\
\hline Mompox & Barranca & 36 & 180 & $\begin{array}{c}1 \text { día } \mathrm{y} \mathrm{medio} \\
(10 \mathrm{~km} / \mathrm{h})\end{array}$ & $\begin{array}{c}2 \mathrm{días} \\
(5 \mathrm{~km} / \mathrm{h})\end{array}$ \\
\hline
\end{tabular}

Fuente: Elaboración propia, con base en Durán, 2012: 115-116.

Además de la ruta por el río Magdalena, hay dos ramales fluviales a Simití y Zaragoza cuyos itinerarios se dan río arriba. El ramal a Simití es muy regular, pero en el itinerario a Zaragoza «por el río Cauca» hay un valor que particularmente sorprende: los $6,43 \mathrm{~km} /$ legua que calculamos de Guazo a Majagual por el río Cauca exceden lo que se podría esperar y algunos kilómetros de la etapa serían por tierra. Alertado por esta irregularidad, revisamos si la geografía ofrece alternativas y resulta que el complejo laberinto del bajo Cauca, con numerosos brazos, pantanos y ciénagas ofrece varias opciones. Así, parece como explicación más lógica que la balsa del correo subió por un pedazo del río San Jorge y el caño Mojona que va con un curso más directo de Guaso hasta Majagual donde debe haber seguido por un caño que hoy parece haber desaparecido pero que se representa en el mapa de 1787, volviendo al Cauca principal en la altura de Algarrobo.

\section{LAS ETAPAS POR TIERRA EN LA PROVINCIA DE CARTAGENA}

Después de llegar a Barranca, el correo siguió a caballo, pasando por Arroyohondo y Santa Cruz, a Mahates. Probablemente siguió a grandes rasgos la carretera que hoy une esas poblaciones. Hay dos mapas valiosos de 1729 y 1753 que, con diferencia a los ya mencionados de 1787 (mapa 2) y 176679,

79 Cf. arriba, nota 41. 
muestran caminos entre Barranca (tanto vieja como nueva) y el sitio de Mahates ${ }^{80}$. En el mapa de 1753 se ve además una bifurcación del camino en Arroyohondo con el texto "Camino real para Cartagena por San Estanislao», que debe ser el camino por el que Cruz Cano dejó pasar el correo en su mapa. También en el último tramo, de Mahates a Cartagena, se encuentra la carretera 90 como aproximación entre Cartagena y Arjona y una carretera menor desde Arjona hacia el dique rumbo a Mahates, quedando solo alguna duda sobre cómo y dónde exactamente se cruzaron las ciénagas y el canal del dique.

En el camino de Cartagena a Santa Marta, los dos documentos de Pando y Miranda, como hemos aludido arriba, parecen describir dos rutas bastante diferentes. La carretera moderna en todo caso toca a San Estanislao y por lo tanto parece asemejarse al recorrido descrito por Miranda para 1801, mientras que el antiguo curso entre Timiriguaco y San Benito queda totalmente especulativo. Incluso el antiguo sitio de San Benito no lo logramos fijar exactamente porque estaba dónde hoy está un embalse. Este embalse también hace difícil la reconstrucción del próximo tramo a Sabanalarga, aunque por lo menos el mapa de 1766 lo muestra pasando por la «punta de Polonia», topónimo también existente hoy en la banda oriental del embalse. Pero solo en la última parte de esta etapa podemos con alguna razón considerar la carretera Sabanalarga-Manatí como aproximación. A partir de ahí, recuerdo, de nuevo hay que considerar dos diferentes recorridos para 1801 y 1774. En 1774 parece que la ruta salió de Sabanalarga siguiendo más o menos la moderna ruta 90, pero no hasta Baranoa sino doblando a Pueblo Nuevo ya con anterioridad. De allá, las carreteras actuales de la vía RioMar y luego la ruta 25 son interpretaciones sensibles. El camino comercial recto, que se volvió a usar en 1801, pasó de Sabanalarga en derechura rumo a Barranquilla. El mapa de 1766 insinúa que alcanzó la ribera cerca de Malambó, pero nuevamente nos faltan carreteras modernas de ayuda. Sea como sea, el curso debe haber sido bastante recto considerando la alta cifra de kilómetros por legua que obtuvimos en el cálculo de las líneas entre los puntos de referencia.

\section{De Santa Marta a Riohacha}

En la provincia de Santa Marta, tenemos dos mapas manuscritos que representan el camino real a Riohacha, uno de 1731 y otro de aproximadamen-

80 Plano y descripción de la costa y provincia de Cartagena [...], 1729, Library of Congress, Geography and Map Division, G5292.C6 1729.P4; Barranca del Rey: Ríos Magdalena, Mahates y Caño del Loro, 1753, AGN-C, SMP.4,REF.31ª 
te $1820^{81}$. Aun así, el itinerario de Pando es una fuente muy importante para reconstruir su trazado. Mientras que el mapa de 1731 muestra un camino que sale de la ciudad inmediatamente al interior, por el río Manzanares, el de 1820 tiene un curso poco común, pasando primero por Taganga, en la costa, lo que supondría toda una vuelta no necesaria (aunque en el mapa aparece como vía recta). El itinerario, considerando las leguas indicadas, parece sugerir el curso más intuitivo por el valle. Las calles 13 y 17 de la ciudad eran las dos que salían de la ciudad hacia el este, luego juntándose extramuros, formando lo que hoy es la Avenida del Libertador ${ }^{82}$. Desde Mamatoco, pasando por Bonda y dos sitios rurales hasta llegar a la otra costa, es evidente que el camino debe haber seguido estrechamente la carretera 90, hasta llegar a la otra costa del mar y allá siguiéndola al este. Los mapas muestran al camino como muy pegado al mar, y también las relaciones de $\mathrm{km} /$ legua son más constantes con un trazado más costero que la autopista actual. Casi todas las etapas del camino caen en nuestra categoría de «leguas cortas», entre 3 y 4,5 km. Sin embargo, hay dos partes donde las cifras de Pando no muestran esa correspondencia, siempre tenemos una etapa demasiado larga seguida por una de legua demasiado corta: Primero, en las primeras dos etapas de Santa Marta a Mamatoco y luego el pueblo de Bonda y entre el río Mendiguaca por el de Buritica al río Diego. Opino que Pando simplemente se equivocó en el orden cuando describió las etapas y ponía las distancias: No solo las longitudes de las leguas tienen más sentido puestos al revés, hay también evidencia textual porque menciona al río de Guachaca como precedente al de Diego ${ }^{83}$, mientras que en realidad se encuentra entre los de Mendiguaca y Buritica y debería haberse descrito en la otra etapa.

Dos detalles más destacan en los informes de Pando y Miranda: Primero, coinciden en el tiempo requerido para recorrer el camino, de cuatro días y medio; y segundo que este tiempo coincide muy bien con las 45 leguas que suman las etapas. Así, llegamos a una cifra calculada de 10 leguas para un día de camino a pie, un buen ejemplo para la igualación de leguas y horas de viaje, calculando con 10 leguas diarias ${ }^{84}$.

${ }^{81}$ Mapa de la costa de la provincia de Santa Marta, 1731: AGN-C, SMP.6,REF.96 ; y Provincia de Santa Marta: AGN-C, SMP.6,REF.54. No tiene fecha, pero su autor es el Luis Francisco de Rieux, gobernador insurgente de Santa Marta a principios de la década de 1820.

82 Cf. el artículo de prensa Padilla Pinedo, 29 de julio de 2016.

83 Pando: $55 \mathrm{v}$.

${ }^{84}$ Cabe decir, en otros itinerarios (no tratados en este artículo) también encontré la práctica de calcular solo 8 horas/día. En los reglamentos de Pando se conocen distancias recorridas a pie de 8,10,12 y hasta 15 leguas diarias que se remuneraban de forma bastante distinta: Los que más recorrían también recibieron más por legua: El chasqui que recorría 15 leguas 


\section{LOS CAMINOS A VALLEDÚPAR}

Para el camino del correo a Valledúpar, tenemos poca información de nuestras dos fuentes textuales principales, que además describen caminos diferentes, aunque ambas se refieren al «camino de Jerusalén», que aparece en la literatura como importante camino contrabandista de Riohacha por Valledúpar a Mompox ${ }^{85}$. Para el camino desde Riohacha, Miranda es poco detallado y se limita a decirnos que son tres días de viaje y que el camino pasa por Barrancas. Hay sin embargo una variedad de mapas de la provincia del Hacha que muestran la red de caminos en la provincia ${ }^{86}$ que nos sirven para establecer por lo menos los sitios y pueblos de Boquerón, Mancomado y Moreno como puntos intermedios, aunque nos faltan carreteras en la actualidad para averiguar un trazado más exacto. De Barrancas, el camino seguramente continuó por la actual ruta 80 pasando por Fonseca y San Juan del Cesar. Para el último pedazo, sin embargo, es prudente suponer que la ruta histórica no coincide con la carretera, sino que pasó por Badillo, lugar que en ambos mapas contemporáneos aparece como punto de referencia en el camino.

La ruta a Valledúpar desde el río Magdalena, indicada por Pando, es todavía más incierta. El problema empieza con las leguas indicadas entre los lugares del itinerario, y luego existe la irregularidad de mencionarse Pueblo Nuevo/Valencia dos veces mientras que falta Valledúpar. Cuatro etapas tienen distancias excesivas, de 8 y $10 \mathrm{~km} /$ legua en línea recta, desproporción que lógicamente aumenta buscando el trazado histórico. Pando ni siquiera se expresa muy claro en cuanto a los medios de transporte, con excepción del primer tramo hasta Chimichagua y Empalagao, que iba por el río y la ciénaga de Zapatosa. Miranda, en cuyo tiempo la ruta ya estaba en desuso, da constancia de que los depoblados y cambios de medio de transporte eran razones para no establecerse allá correo ordinario. Lo que podemos afirmar con certeza por el itinerario de Pando es que no siguió la ruta por Jagua, Becerril y la cadena de pueblos de misión por el lado de la sierra, donde hoy está la carretera 49, sino que iba por El Paso en la otra banda del río Cesar. El mapa de Rieux de $1820^{87}$, el único que nos podría ayudar al respecto, tampoco es

recibió dos reales y medio por legua, el de ocho leguas solo un real (Pando: 29r-v). Aun así, juzgo que el día de a diez leguas era lo más común en el Nuevo Reino.

85 Peñas Galindo, 1995.

86 Para solo dar unos pocos ejemplos: Mapa general de la Provincia de yndios Goagiros, 1773, AGI, MP-Panama,184; Mapa General de la Provincia de la Hacha, 1776, AGI, MP-Panama,190BIS; Mapa de la provincia de la Hacha, 1819, AGI, MP-Panama,325.

87 Cf. arriba, nota 81. 
muy revelador. Ese mapa muestra como camino más recto el ya descartado por Becerril. La vía por El Paso a Valencia en el mapa sigue un repliegue muy marcado, yendo rumbo al norte primero y luego al este. Aparecen diferentes haciendas y topónimos - como Caracolí y María Angola- que podemos ubicar en la actual carretera 80 entre Bosconia y Valledúpar, y así parece que el punto de cruce del mapa (Guayacanes), podría corresponder más o menos a Bosconia. Pero por este rumbo, la distancia correspondiente a una legua aumentaría a $13 \mathrm{~km}$. En suma, la reconstrucción de la ruta por estos despoblados, en la que seguramente faltó un «camino formal» queda por el momento totalmente especulativa. Como hipótesis para explicar las leguas largas se ofrece nuevamente suponer horas de viaje (¿a caballo?), de alguna forma convertidas a leguas.

\section{LOS CAMINOS A OCAÑA}

En cuanto a los caminos a Ocaña contamos nuevamente con el apoyo del mapa de Rieux, pero también de otro, hecho en 1764, centrado completamente en la jurisdicción de Ocaña.

Recordamos que Pando ofrece dos itinerarios distintos para llegar a Ocaña desde el río Magdalena. El camino ya remplazado en 1774 se representa en el mapa de 1764 hasta la hacienda de Marqués (hoy Guamalito) y todavía hoy existe una carretera que une los lugares del itinerario. También el resto del camino está bien fijado por las carreteras que de Guamalito pasan por El Carmen (=Estancia vieja) y San Antonio hasta Rio de Oro y Ocaña. Así, conocemos con bastante detalle el trazado, pero las leguas indicadas no tienen ningún sentido: 3 leguas para los $36 \mathrm{~km}$ desde Simaña a Marqués, subiendo y bajando una sierra son un valor bastante absurdo, y la misma cifra luego se da para los 8 kilómetros siguientes en el camino que sigue el arroyo entre Marqués y Estancia vieja. Lo interesante es que la relación para el camino completo con algo más de $4 \mathrm{~km} /$ legua está bastante bien calculada, por lo que parece posible que las distancias de las etapas individuales se ponían al azar o Pando, copiando alguna fuente, se equivocó de alguna forma.

La ruta nueva, desde Morales, es más difícil de fijar. Mientras que, en el primer camino, la duda está casi exclusivamente en cómo Pando llegó a sus medidas de distancia y no en cuanto al trazado concreto, en el segundo camino la incertidumbre se extiende también sobre este aspecto. Pando informa que la primera etapa de Morales - en un brazo del Magdalena - a Puerto Real de las bodegas de Ocaña - en el río principal - se hizo en barco y no por tierra cruzando la isla de Morales. Esto sorprende porque la distancia por 
Mapa 6. Región de Ocaña, entre el Magdalena y Catatumbo (1764)

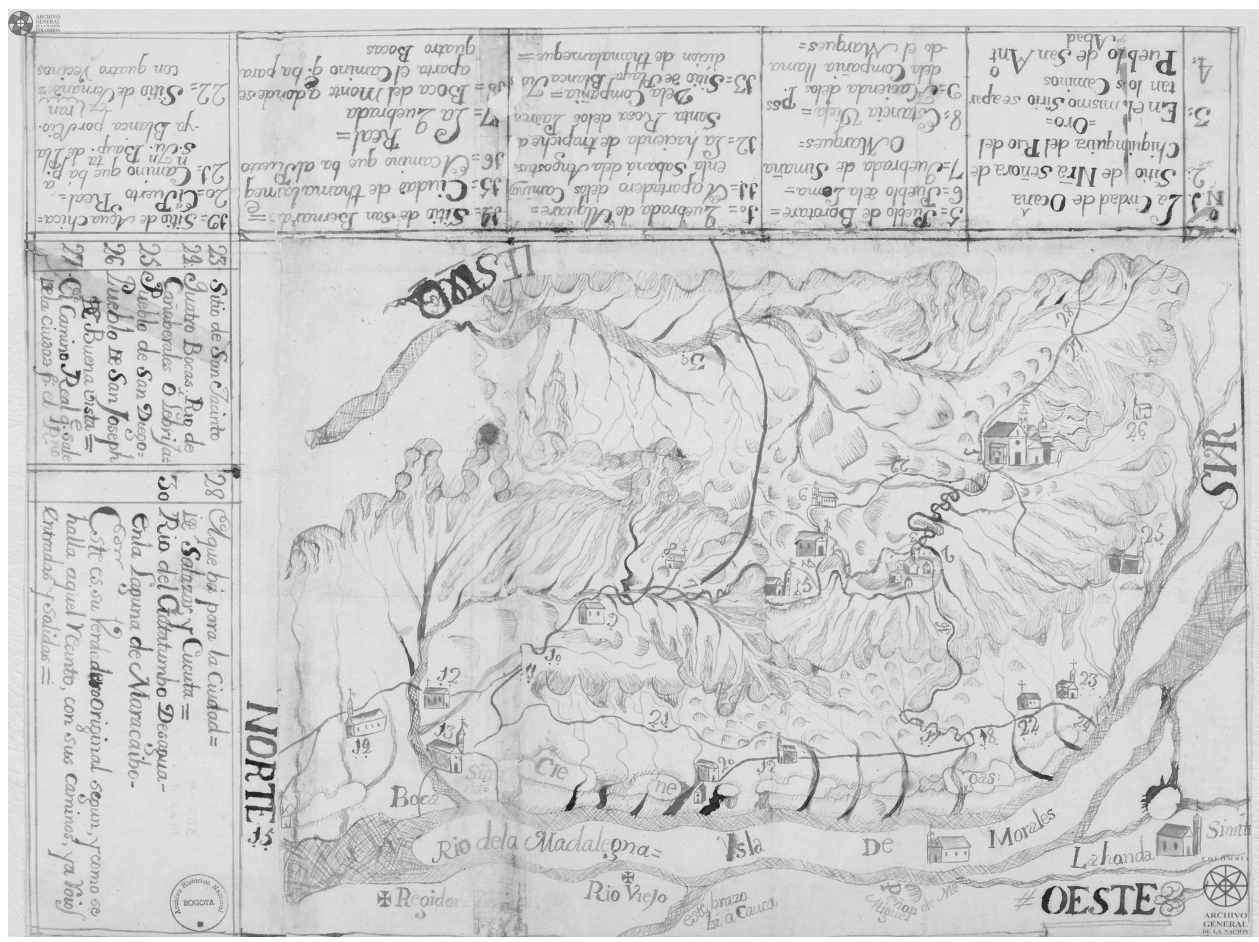

Fuente: Región de Ocaña, entre el Magdalena y Catatumbo, 1764, AGN-C, SMP.4,REF.302a .

tierra es de apenas $16 \mathrm{~km}$, mientras que el barco necesitó un día ${ }^{88} \mathrm{o} \mathrm{dos}^{89}$ para los $25 \mathrm{~km}$ río arriba y otros 40 río abajo. Para el camino por tierra desde el Puerto Real, pasando por Agua-Chica, se ofrece como mejor aproximación la moderna carretera 70. Sin embargo, también hay indicio al contrario en el mapa de 1764: parece insinuar que desde Agua-Chica la ruta siguió rumbo al sur, hasta una anónima «Quebrada» camino a Cuatro Bocas para luego subir a la sierra hasta Rio del Oro. Además, en la historiografía local, se menciona un «camino de la camarona», que salió de Ocaña no al norte por Rio del Oro sino más directamente por Venadillo, luego tomando un curso más austral que la carretera 70 pasando por Diego Hernández, Los Ángeles y Totumal a Agua-chica, y de allá al Puerto Real. ${ }^{90}$ Miranda definitivamente menciona que

\footnotetext{
88 Miranda: 5v.

89 Pando: 49r; nuevamente, calculando diez leguas por día.

90 Casadiego, 2011.
} 
el correo pasó por Río del Oro. Entonces, creemos que en 1801 el correo habrá seguido más o menos la carretera 70, pero para la década de 1770 no podemos juzgar si fue así o si el correo entró en Ocaña por el suroeste.

\section{De Portobelo a Panamá}

Un problema particular para la reconstrucción de los caminos ístmicos son las masivas intervenciones humanas del siglo XX: Largas partes de lo que era el camino de Cruces hoy forma parte del Canal de Panamá, mientras que el antiguo camino real se ve interrumpido e inundado por el embalse del Lago Madden/Alajuela.

\section{Mapa 7. Detalle de la CaRTa marítima del ReYNo} DE TIERRa FiRMe de JuAn LóPEZ (1785) y GeORRECTIFICACIÓN DEL MAPA

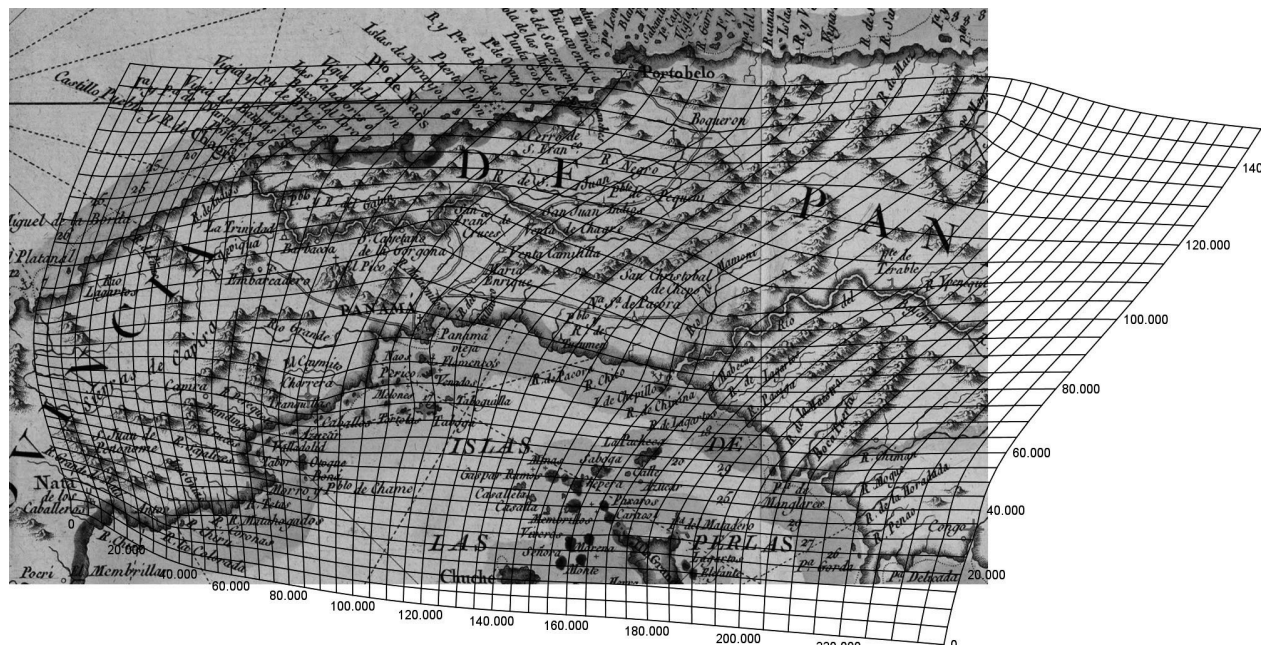

Fuente: Elaboración propia sobre la Carta Maritima (nota 91).

Hay algunas representaciones cartográficas de los caminos ístmicos de la época, aunque tampoco son muchas. El mapa mejor conocido con esta característica es seguramente el de Juan López de 1785 (mapa 7) ${ }^{91}$. Un problema

91 Carta Maritima del Reyno de Tierra Firme ú Castilla del Oro. El original está en la Biblioteca Nacional de España, Sala Goya, una copia digital accesible en http://bdh.bne.es. 
del mapa es que, en su afán de modernizar la cartografía del istmo, se apoyó demasiado en mapas franceses e ingleses, que a primera vista representan las costas de Tierra Firme con mayor exactitud que los españoles, pero que se equivocaron con respecto a las longitudes. Así, Portobelo en el mapa queda muy al oriente de Panamá, mientras que en realidad (y como lo mostraron más correctamente los mapas españoles) están más o menos en una misma longitud ${ }^{92}$. Esta distorsión se hace particularmente visible a través de un alineamiento de puntos de referencia del mapa con una cuadrícula geodésica.

Además, hay otro mapa que se centra explícitamente en los caminos transístmicos, del que hay dos ejemplares prácticamente idénticos ${ }^{93}$. Según la Biblioteca del Congreso es de aproximadamente 1780, el Archivo Nacional colombiano lo data simplemente para el siglo XVIII. La mayor diferencia entre los dos ejemplares es que el del Archivo Nacional lleva cartucha con autor, Tomás Ramery, lo que nos permite datar el mapa para los primeros años de la década de 1790, cuando Ramery visitaba Cartagena y Panamá. Además, fue inspector de las islas de San Andrés y Santa Catalina en 1793. El mapa es de particular valor porque es la única fuente que contiene varios topónimos presentes en los itinerarios de Pando y que así se han podido localizar con alguna confianza.

Otros mapas relevantes para la reconstrucción son los que muestran la antigua línea ferroviaria construida a mediados del siglo XIX y los levantados en tiempos de la construcción del canal ${ }^{94}$. Permiten una buena aproximación al curso histórico del río Chagres y los puntos de confluencia con otros ríos y caminos existentes en ese entonces ${ }^{95}$. Georrectificando estos mapas usando

Otro mapa que muestra este camino, aunque sea de forma muy generalizada, es el Mapa que demuestra lo que berdaderamente es la Provincia de la Nueva Castilla del Oro, y por otro nombre del Darien, 1795, su autor es Miguel Andrés García. También de este mapa hay copia digital en el sitio arriba citado. Irónicamente, García era administrador de correos de Panamá, pero no tenemos mapa postal de él, sino solo ese, producido en el marco de un proyecto colonizador que proponía.

92 Esta cuestión sobre la posición relativa de las dos ciudades ya se debatía por Jorge Juan y Antonio de Ulloa en la descripción de su viaje por el istmo. Juan y Ulloa, 1748, libro III, cap. II, 254.

93 Plano geográfico de la costa de Tierra Firme desde Bastimentos hasta el Río Chagres, AGN-C, SMP.6,REF.47; Map of central Panama showing Chagres River and its tributaries, Library of Congress, G4872.C5 1780 .M3: https://www.loc.gov/item/90680519/.

94 Map Showing Location of Panama Canal, National Geographic 1905, Harvard Library Map Collection, en línea: http://www.oldmapsonline.org/map/harvard/4688096.

95 Metodológicamente, este procedimiento corre el riesgo de autoafirmar sus resultados cuando la localización de un punto se hace sobre un mapa georreferenciado y luego se georrectifica otro mapa usando ese punto como referencia. Aunque a veces frustra, la selección de puntos de referencia conocidos debe ser en un todo separado de la labor comparativa. 
Mapa 8. MaPa del istmo de Panamá POR Tomás Ramery (CA 1790)

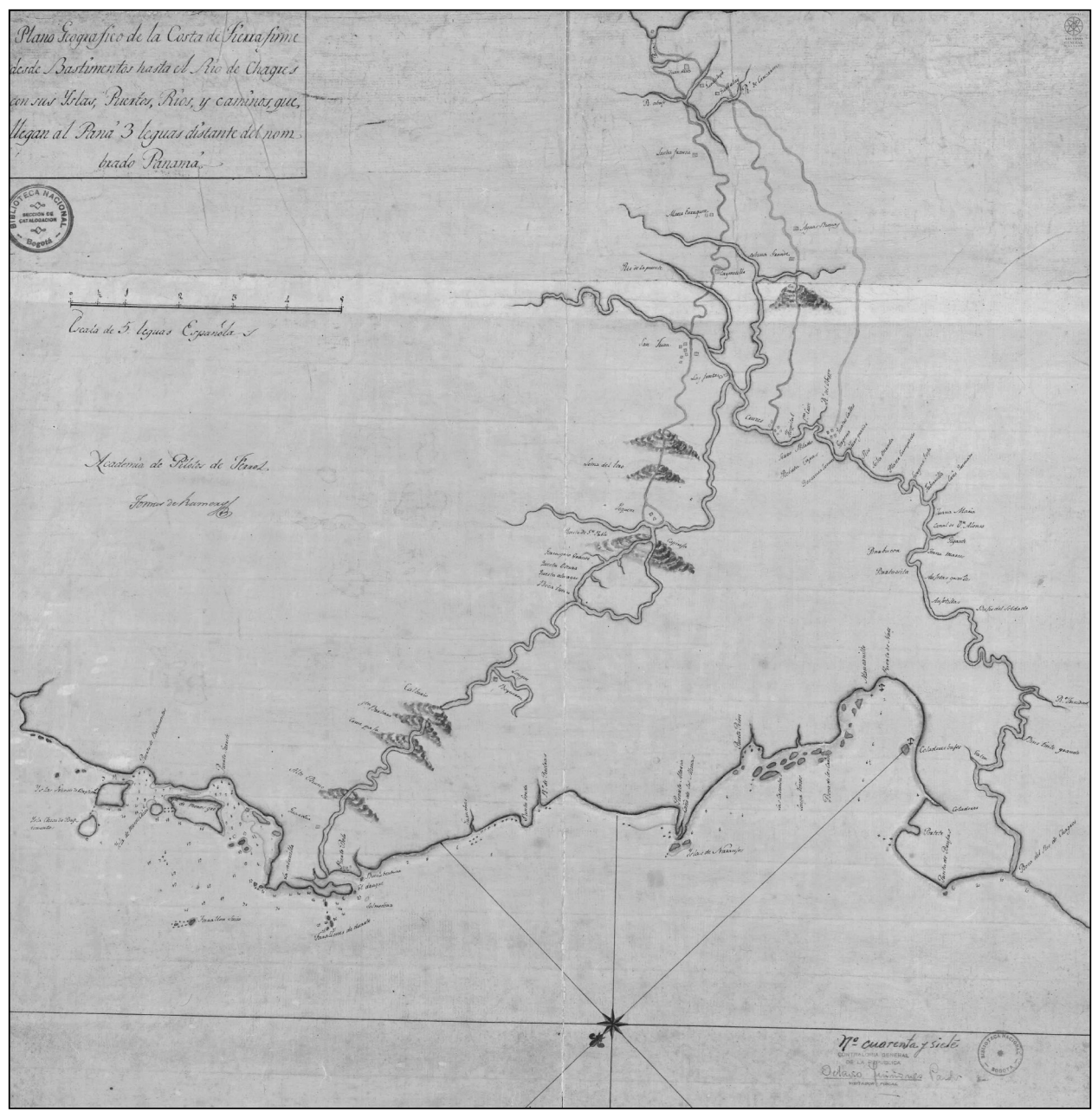

Fuente: Plano geográfico (nota 93).

topónimos conocidos, se pueden digitalizar también los caminos terrestres. Esta operación pone en evidencia que Ramery debe haber trabajado sobre un original antiguo. En el título del mapa dice que muestra los «caminos que llegan al Paná 3 leguas distante del nombrado Panamá». Haciendo la georrectificación, queda evidente que tal «Paná» debe ser Panamá viejo, abandonado ya en 1671. Esta hipótesis se apoya en que con esta localización se distorsiona muy poco el mapa, y también lo pone en evidencia el topónimo de Juan 
Días representado en el mapa, hoy un barrio que se encuentra cerca a Panamá viejo. Una curiosidad del mapa - que además nos muestra claramente que Ramery no recorrió el terreno para elaborar el mapa, sino que lo hizo desde la oficina- es que aparentemente malinterpretó las líneas de su fuente, representando al tramo entre Pequení por Boquerón a Portobelo como vía fluvial, además conectada con el sistema del río Chagres. Seguramente tenía más que una fuente cartográfica para hacer su mapa, porque no toda información parece referirse a una situación anticuada del siglo XVII, como evidencia la representación del camino de Gorgona - una alternativa al de Cruces-, que se oficializó como camino comercial solo después de 1735. A la habilitación de este camino debemos la existencia de un mapa más - preservado en el Archivo General de Indias - que nos sirve de comparación y que se hizo para ilustrar esa nueva ruta en comparación con el camino tradicional de Cruces ${ }^{96}$.

Tenemos la increíble suerte de poder evaluar la solidez de nuestro método de reconstrucción gracias a un esfuerzo notable realizado por el austríaco Christian Strassnig. Durante años trabajó en el rescate del patrimonio cultural del camino real, buscando por los vestigios materiales del antiguo camino, realizando intensivos reconocimientos del terreno, recordando los posicionamientos GPS de los restos del camino, perdido en la selva. Hoy, Strassnig valoriza sus hallazgos en una empresa para senderismo y ecoturismo sostenible, apoyando también comunidades de la zona ${ }^{97}$. Comparando la ruta GPS a los demás datos, la coincidencia con el camino de Cruces del mapa de 1905 es muy alta -el trazado según el mapa está un poco más al oeste, pero con una distancia nunca mayor que $600 \mathrm{~m}$ - En cambio, la digitalización de los mapas coloniales muestra diferencias algo mayores entre 1 y $2 \mathrm{~km}$ en la parte norte, debido a la localización de las haciendas de Sabana Grande y Agua Buena, la última puesta sobre la población moderna homónima, que tal vez deberían localizarse algo más hacia el suroeste. La comparación con el mapa de Ramery es la más dificil porque esta parte del mapa es la de mayores distorsiones, por lo que la elección de puntos de referencia influye mucho en el resultado y padece de la misma duda con respecto a la localización de Sabana Grande y Agua Buena.

En cuanto al camino real, la correspondencia de la georrectificación con el GPS es todavía mejor: Las líneas se cruzan varias veces entre Portobelo y Boquerón, con distancias que nunca superan al kilómetro. Al sur de Boquerón,

96 Plano Geographico desde la ciudad de Panamá hasta el Rio de Chagre comprehendido el terreno en que están situados los caminos a los sitios de Cruces y la Gorgona...: AGI, MP-Panama, 137.

97 Strassnig, 2010. Este autor ha fundado una empresa de ecoturismo que ofrece excursiones de senderismo por el camino real de dos o cuatro días: www.cultour.info. 
las diferencias son algo mayores por una distorsión del mapa no contabilizada a falta de puntos de referencia. Entre la confluencia del Chagres al Pequení hasta la Venta de Chagres, el mapa georrectificado sugiere un curso un kilómetro y medio más alejado del río de lo que en realidad era. Al sur de la Venta de Chagres, tenemos otro tramo de coincidencia muy alta, con diferencias menores a los 500 metros hasta lo que hoy es Villa Zaita. Allá, como es lógico, termina la coincidencia porque el camino reconstruido por Strassnig pasa a Panamá nuevo y el del mapa a Panamá viejo.

\section{De Panamá al resto de Tierra Firme}

El itinerario de Pando, recordamos, en Tierra Firme no describe una carrera de correo - pues no existía - sino simplemente el itinerario del camino real a Veraguas y luego por la provincia de Chiriquí rumbo a Costa Rica; solo hacia 1785 se realizó la carrera de correo ordinario hasta Veraguas. Los lugares de ambos itinerarios - Pando y Miranda - son los que también se conectan hoy por la carretera Interamericana. Solo entre Antón y Natá, el itinerario de Pando tomó un camino más recto, mientras que en la descripción de Miranda ya pasa por Penonomé, por donde también hoy pasa la Interamericana. La variación de las distancias por legua de las etapas individuales entre las dos fuentes es algo mayor que en la provincia de Cartagena, pero solo pocas irregularidades requieren de explicación en cuanto al trazado del camino. Solo entre Penonomé y Natá las cinco leguas indicadas por Miranda serían muy largas $(6,8 \mathrm{~km})$ siguiendo la Interamericana, por lo que es probable que el camino histórico tomara un rumbo más directo.

$\mathrm{Al}$ occidente de Veraguas la situación es diferente porque el itinerario muy probablemente salió de Veraguas más al sur de donde hoy pasa la Interamericana, por caminos locales que llegan más directamente a La Mesa. El siguiente punto de referencia, Bijagual, es prácticamente desconocido. Con alguna suerte encontramos una «Quebrada Bijagual» en GeoNames, cerca de Buenaventura de Las Palmas, pueblo de misión fundado en 1771. Mi interpretación es que Buenaventura se fundó en la Quebrada Bijagual y que el punto en el itinerario corresponde al sitio de ese pueblo o un lugar muy cercano. El siguiente pueblo, San Rafael, tenía una existencia muy precaria en el siglo XVIII ${ }^{98}$. No he logrado ubicar su situación más exacta, pero su representación sugiere que estaba en la zona donde se fundaron San Antonio del Guaymí en 1771 y Tolé en 1775. Las leguas resul-

98 Aparentemente ya se despobló en la década de 1720, pero sigue presente en mapas posteriores. Arauz, 1980: 177-178. 
tantes en estas etapas son algo cortas, pero es posible que simplemente había más serpentinas en la ruta de lo que hemos tomado en cuenta. Al contrario, las dos etapas entre Remedios y David tienen leguas de aproximadamente $7 \mathrm{~km}$, por lo que me inclino a pensar que las leguas del itinerario a partir de Veraguas otra vez corresponden a (o por lo menos se influyen por) horas de viaje. Pero no por esto el análisis de la relación $\mathrm{km} / \mathrm{legua}$ es irrelevante: Alertado por una irregularidad muy marcada en las leguas de las última dos etapas - la primera de legua muy larga, la segunda muy corta - me hizo revisar la localización del pueblo de Boquerón y resulta que aparentemente el pueblo se había trasladado en 1767 a su lugar actual $-\mathrm{y}$ el itinerario todavía refleja su ubicación anterior, más cercano a Alange - . Tanto la mención de San Rafael como la posición de Boquerón son evidencia de que el itinerario de ese camino de la provincia de Veraguas no se basó en una fuente reciente sino en información ya anticuada para 1774.

Para el ramal del correo a Los Santos y Las Tablas — establecido, recordamos, hacia 1785 - lamentablemente Miranda no informa sobre la distancia de las etapas individuales, pero hay una carretera muy lógica que se ofrece como aproximación. En la parte oriental de la provincia de Panamá y en el Darién, las inconsistencias de las distancias indicadas por Pando y la falta de carreteras modernas pavimentadas dificultan la interpretación. Los caminos de Panamá hasta Chepo todavía están en los parámetros de las demás rutas, pero de Chepo a Pásiga solo especulamos que el camino puede haber ido por una cadena de haciendas hasta Terablé, un fuerte para proteger la provincia de los darienes, y de allá al sur - ejercicio que también resulta en unas leguas razonables, pero no por esto deja de ser muy especulativo-. La última etapa, supuestamente por tierra, entre Pásiga y Chimán no hace ni mínimo sentido ante la falta de carreteras y caminos, una difícil geografía y varios ríos por cruzar - que en línea recta serían 7,8 km/legua- Los itinerarios correspondientes a la provincia del Darién no los escrudiñamos aquí con detalle porque, donde no seguían los ríos, faltan mapas de la época y carreteras modernas para interpretar su curso y las distancias de leguas para sí no son suficientes para una reconstrucción fiable.

\section{Cumplimiento DE LA REAL CÉDUlA}

Con la información reunida digitalizamos una nueva interpretación de las rutas recorridas por los correos y luego sujetamos el resultado nuevamente a análisis estadísticos. Los siguientes dos gráficos, organizados según el medio de transporte y fuente de información, muestran las relaciones de kilómetros por legua de las etapas individuales después de la conversión de las líneas rectas en trazados concretos. 


\section{GRÁFICO 1. RELACIÓN KM/LEGUA DE ETAPAS POR AGUA}

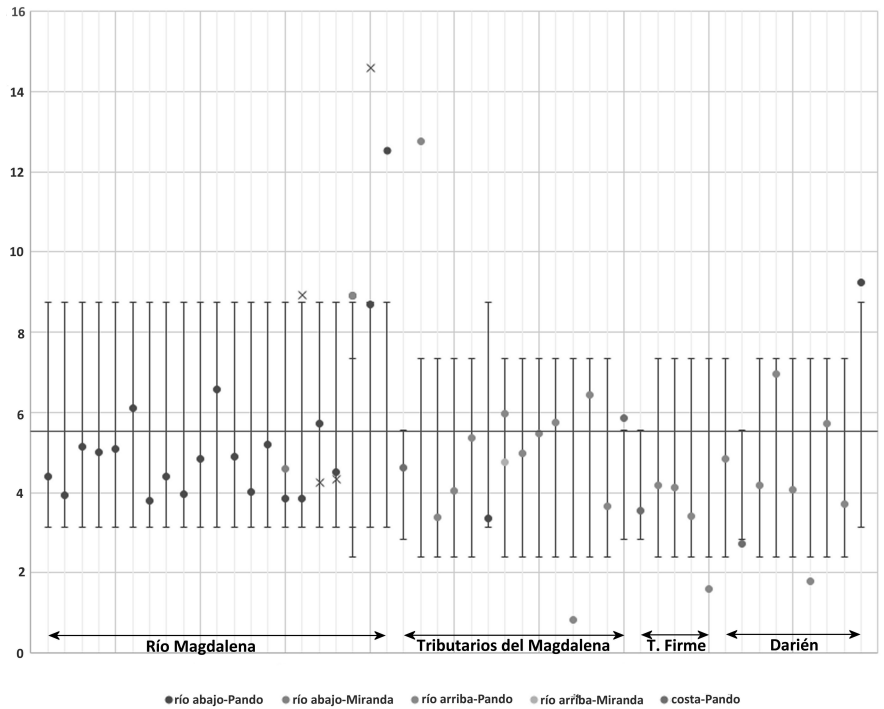

Fuente: Elaboración propia con base en el Manuscrito de Pando y la Relación de Miranda.

\section{GRÁFICO 2. RELACIÓN KM/LEGUA DE ETAPAS POR TIERRA}

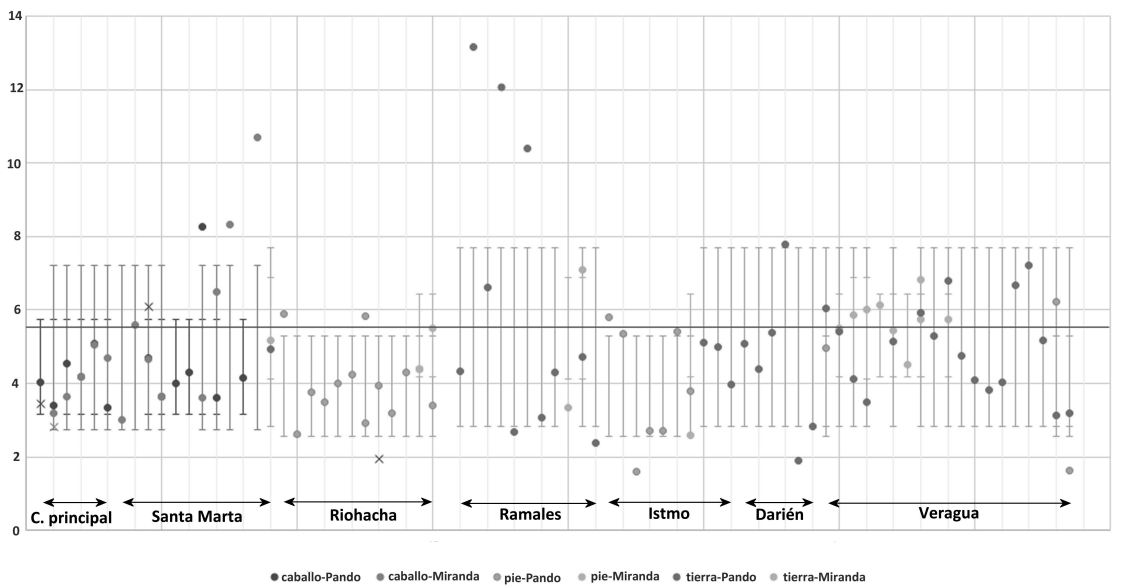

Fuente: Elaboración propia con base en el Manuscrito de Pando y la Relación de Miranda.

Nota: Los valores con cruces en vez de círculos son aquellos datos que se calcularon sobre una reconstrucción inicial pero que se corrigieron debido a las inquietudes ocasionadas por los cálculos. 
Es muy revelador un tercer gráfico que agrupa las etapas simplemente según las leguas indicadas.

\section{Gráfico 3. Promedios De KM/Legua Según LEGUAS POR ETAPA}

\section{km/legua según leguas por etapa}

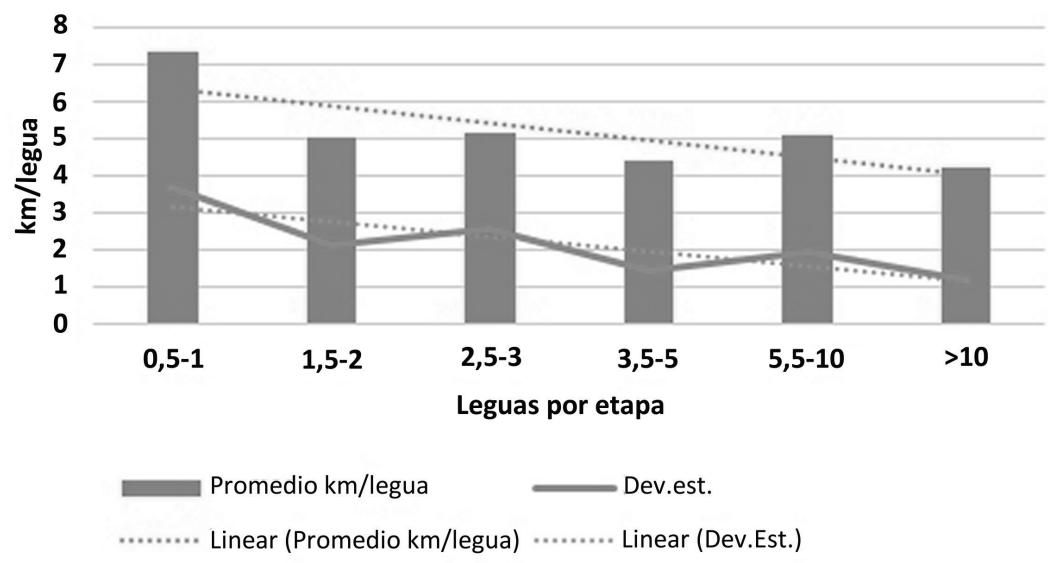

Fuente: Elaboración propia con base en el Manuscrito de Pando y la Relación de Miranda.

Se nota que las irregularidades estadísticas se concentran sobre todo en las etapas de media legua o legua, con un alto promedio y alta deviación estándar. En cambio, las demás categorías tienen promedios y deviaciones equiparables, con solo una liviana tendencia diminutiva. Este detalle se explica fácilmente: por un lado, «una legua» en muchos itinerarios era la cifra mínima, por lo que también valores muy bajos se indicaron como una legua. Además, obviamente la decisión entre indicar una legua o dos leguas es estadísticamente mucho más relevante que la decisión entre 19 o 20 leguas.

Hay que confesar que no ha sido posible resolver todas las contradicciones intrínsecas de las fuentes con la información existente. Por lo tanto, el grado de confianza en cuanto a los trazados de los caminos varía mucho de caso en caso. Pero a la vez es justamente debido a la labor comparativa y el cómputo de variados análisis espaciales que muchas de esas contradicciones se lograron identificar desde un principio, irregularidades que hasta la fecha no se habían discutido. Los métodos empleados para el caso de Cartagena también pueden ser plantilla para similares trabajos en otras partes del doble-continente americano para completar el cuadro en lo sucesivo. 
Mapa 9. Mapa postal de Cartagena, ca 1774

Itinerarios de correo en Cartagena y Santa Marta (1774)

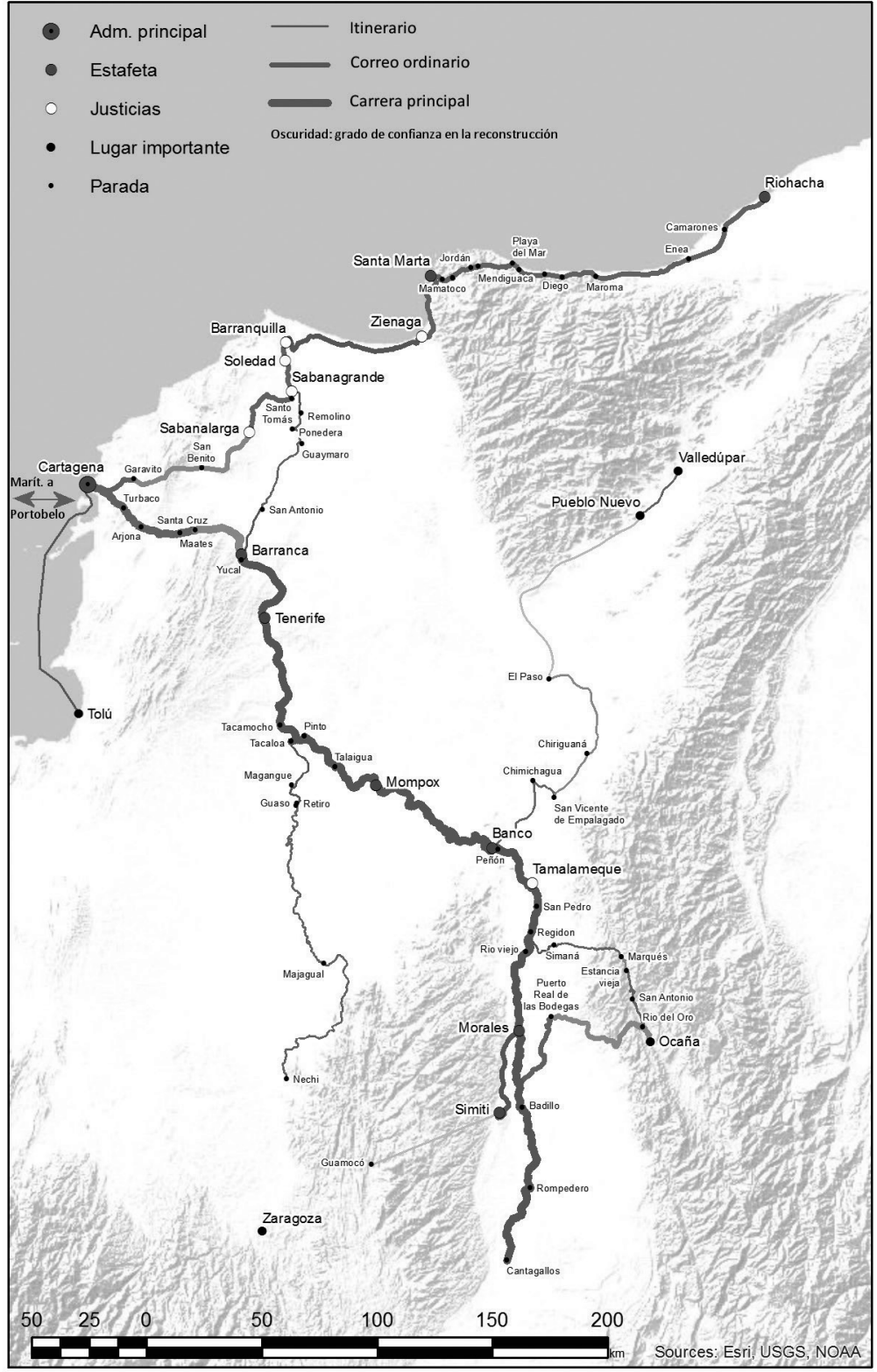

Fuente: Elaboración propia.

Revista de Indias, 2020, vol. LXXX, n. ${ }^{\circ} 278,199-250$, ISSN: 0034-8341

https://doi.org/10.3989/revindias.2020.007 


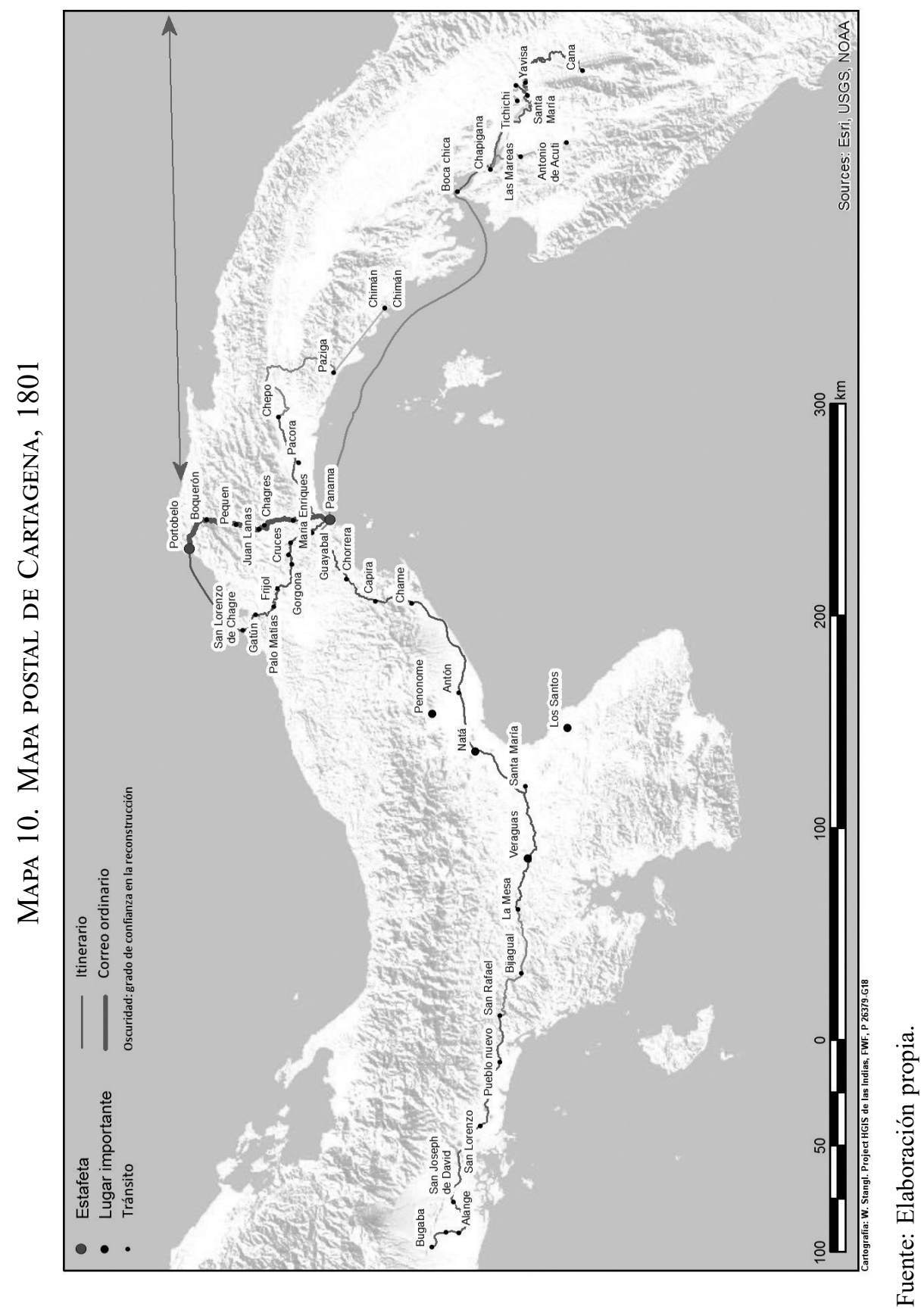

Revista de Indias, 2020, vol. LXXX, n. ${ }^{\circ} 278,199-250$, ISSN: 0034-8341 https://doi.org/10.3989/revindias.2020.007 
Mapa 11. Mapa postal de Tierra Firme, Ca 1774

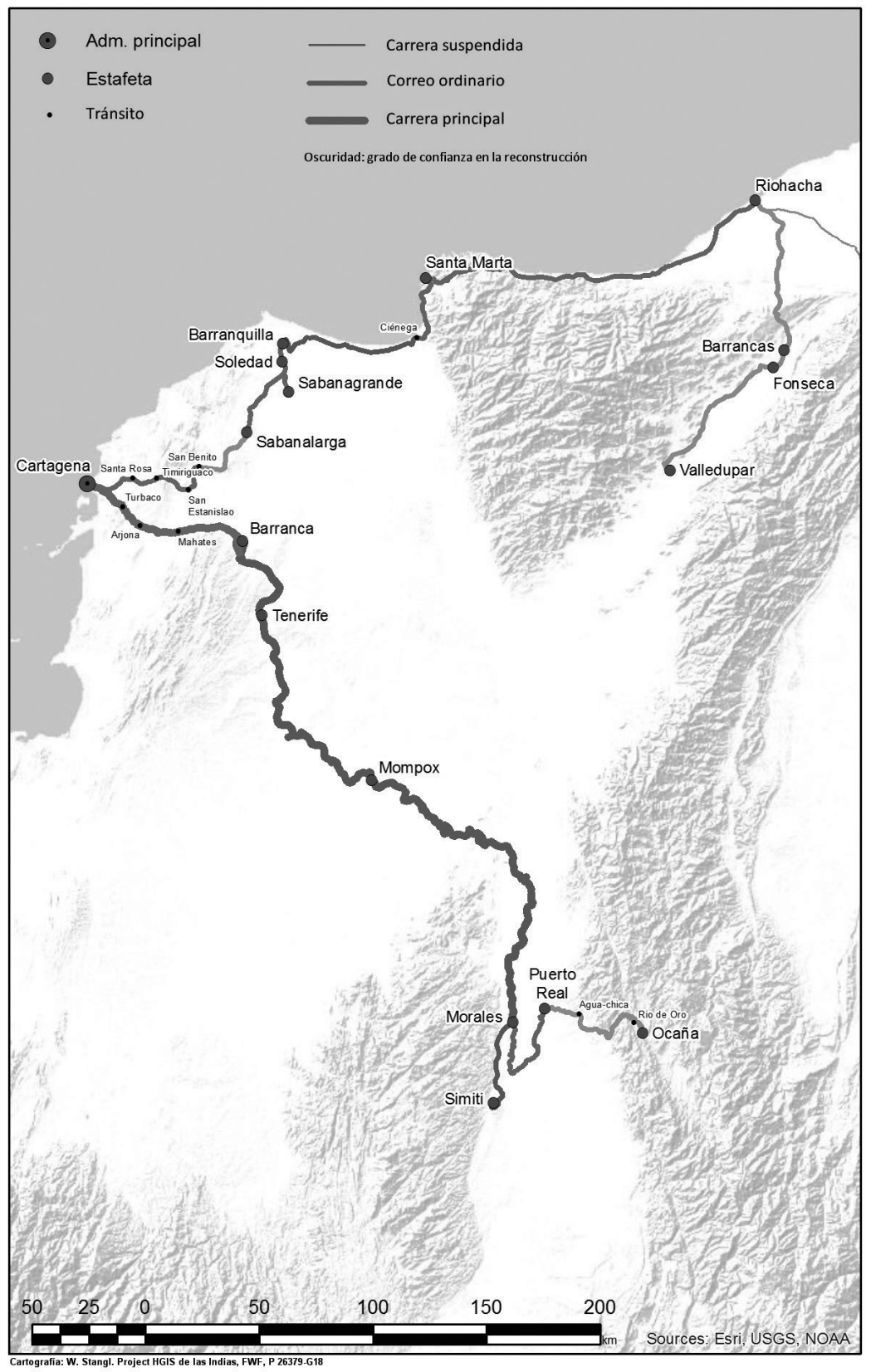

Fuente: Elaboración propia.

Revista de Indias, 2020, vol. LXXX, n. ${ }^{\circ}$ 278, 199-250, ISSN: 0034-8341

https://doi.org/10.3989/revindias.2020.007 


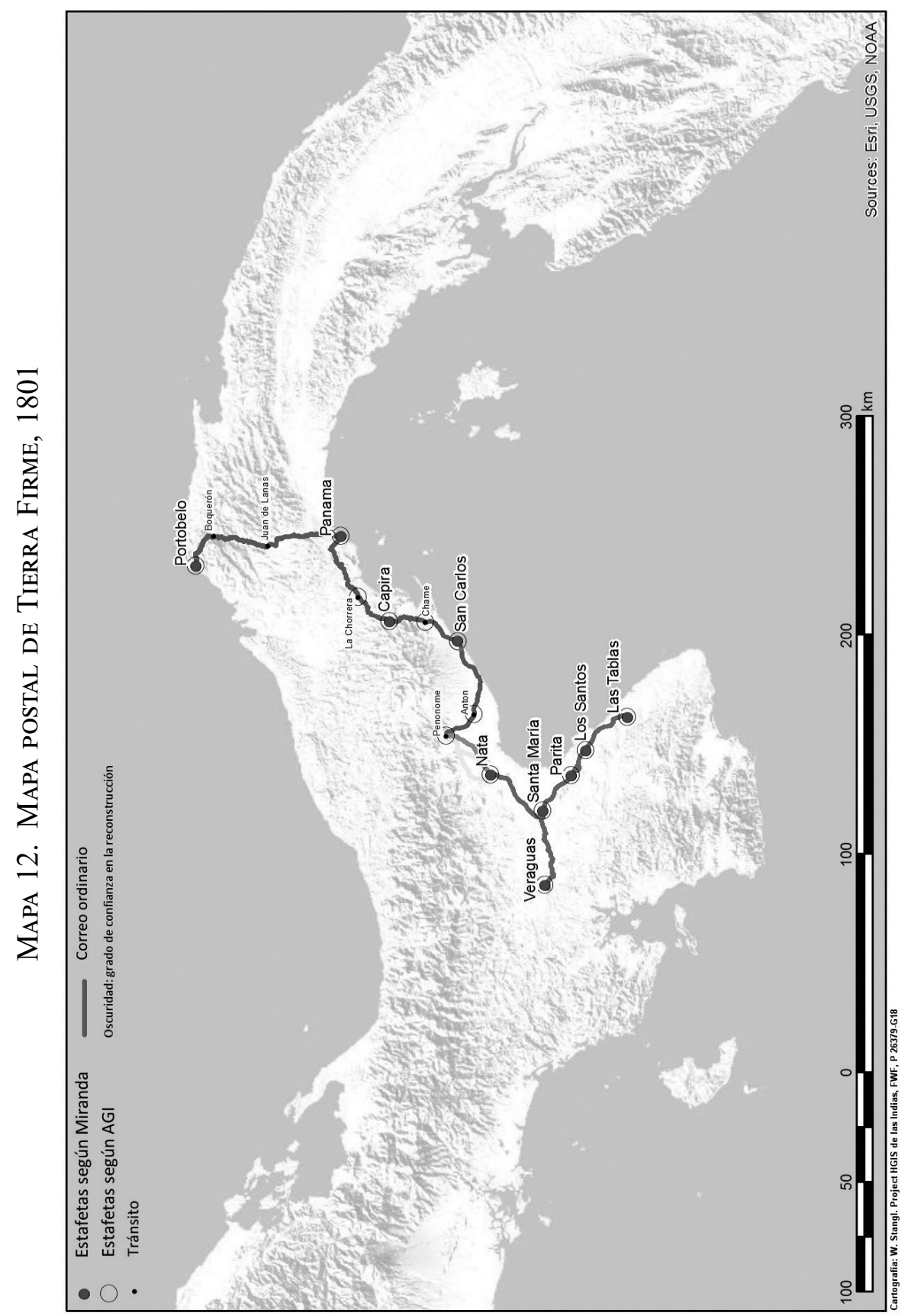

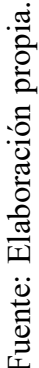

Revista de Indias, 2020, vol. LXXX, n. ${ }^{\circ}$ 278, 199-250, ISSN: 0034-8341 https://doi.org/10.3989/revindias.2020.007 
MaPa 13. MaPa General de las costas atLÁnticas del VirReinato de Santa Fe a fines del Siglo XVIII

La región atlántica del Virreinato de Santa Fe a fines del siglo XVIII

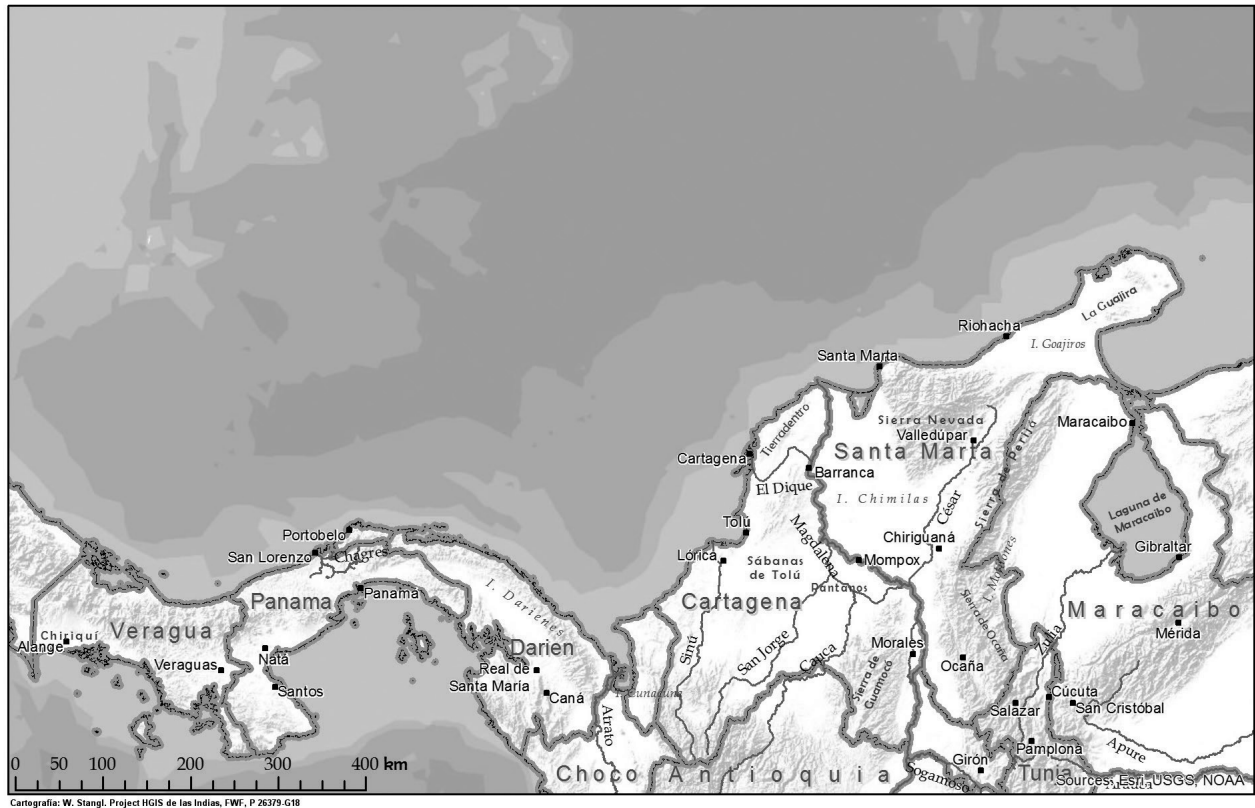

Fuente: Elaboración propia.

Además, espero que las aproximaciones pueden ser también de ayuda para esfuerzos similares al de Strassnig en Panamá en cuanto al rescate y la valorización del patrimonio cultural de esas rutas y los caminos reales. La comparación de los caminos ístmicos ha mostrado con claridad que la reconstrucción a través de itinerarios y mapas georrectificados puede resultar en aproximaciones bastante fiables y limitar el área en el que luego pueden buscarse vestigios arqueológicos de esas redes de comunicación.

Con las informaciones reunidas, podemos finalmente cumplir con la real cédula del 25 de octubre de 1794, con más de dos siglos de atraso, y presentar una cartografía para la administración general de Cartagena en tiempos de la renta real, en una serie de cuatro mapas postales.

\section{FUENTES}

AGI $=$ Archivo General de Indias 
AGN-C = Archivo General de la Nación (Colombia)

Descripcion o Mapa en relazion topografica de las administraciones de correos y tavacos de el departamiento de Cartagena de Yndias, AGN-C, Correos-Bolivar 4, d. 28.

Reales ordenanzas, instrucciones, y reglamentos aprobados para el Gobierno, y manejo de la renta de estafetas, correos, y postas del reyno del Peru, y Chile, s. 1. [Lima], s. a. [1778 o 1779].

Servicio histórico militar, Cartografía y relaciones históricas de ultramar. Carpeta V. Colombia, Panamá, Venezuela, Madrid, Servicio geográfico del Ejército, 1980.

\section{BIBLIOGRAFÍA}

Alcázar, Cayetano, Historia del Correo en América, Madrid, Sociedad de Historia Hispano-Americana 1920.

Alonso, Fernando y López Bernal, José Manuel, “Correo y cartografía. Selección de mapas postales (1760-1856)”, Academvs, 4-8 y 10-14 (Madrid, 2002-2010).

Aranaz del Río, Fernando, "Cartografía postal española", Academvs, 4-8 (Madrid, 2002-2004).

Araneda, José, "Los correos como agentes de cambio. Actores postales en la reforma de las comunicaciones imperiales", Nuevo Mundo, Mundos Nuevos (París, 2017). https://doi.org/10.4000/nuevomundo.71552

Arauz, Celestino Andrés, et al. (eds.), La historia de Panamá en sus textos, tomo I: 1503-1903, Panamá, Editorial universitaria, 1980.

Arbellot, Guy, Autour des routes de poste. Les premières cartes routières de la France, París, 1992.

Baudot Monroy, María, "Maritime post routes between Corunna and the Caribbean as a Geographic Information System (Gis) model", Culture \& History, 4/2 (Madrid, 2015): e021. https://doi.org/10.3989/chdj.2015.021

Bose, Walter, Historia del Correo de España y Hispanoamérica, Buenos Aires, s. d. [1951].

Casadiego, Benjamín, Espacio, tiempo y memoria. Historia y arquitectura en la región de El Carmen. Norte de Santander, s. 1., Gobernación del Norte de Santander/ Alcaldía de El Carmen/Funeducar, 2011. http://uploads.worldlibrary.net/uploads/ pdf/20141003162319el_carmen_espacio_tiempo_y_memoria_pdf

Castro Estevés, Ricardo de, Historia de Correos y Telégrafos de la República Argentina, Buenos Aires, Dirección General de Correos, 1938.

Durán y Díaz, Joaquín, Estado general de todo el virreynato de Santafé de Bogotá de 1794, s. 1. [Santafé de Bogotá], 1794 [ed. facs.: Bogotá, Banco de la República, 2012]. 
Garay Unibaso, Francisco, Correos maritimos españoles, 4 vols., Bilbao, Ediciones Mensajero, 1987-1996.

González Martínez, Nelson Fernando, "Comunicarse a pesar de la distancia: La instalación de los Correos Mayores y los flujos de correspondencia en el mundo hispanoamericano (1501-1640)", Nuevo Mundo, Mundos Nuevos (París, 2017). https://doi.org/10.4000/nuevomundo.71527

Jiménez Carcés, José Andrés, La obra del cartógrafo Cano y Olmedilla y su mapa de la América meridional de 1775, tesis doctoral, Madrid, Universidad Complutense de Madrid, 2016. http://eprints.ucm.es/37926/1/T37329.pdf

Juan, Jorge y Ulloa, Antonio de, Relación del viaje a la América meridional, primera parte, tomo primero, Madrid, Antonio Marín, 1748.

López Bernal, José Manuel, El correo marítimo colonial. Rutas y tarifas postales Madrid, Real Academia Hispánica de Filatelia, 2011.

López Bernal, José Manuel, Mayo, Leoncio, Sitjà, Jesús, Harris, Leo J., Gruson, Cécile, Gallegos, Guillermo F. y Kouri, Yamil H. Jr., Los correos mayores de Yndias, San Sebastián, Rústica, 2014.

López Gómez, Antonio y Manso Porto, Carmen, Cartografía del siglo XVIII: Tomás López en la Real Academia de la Historia, Madrid, Real Academia de la Historia, 2006.

Molina Montes de Oca, Carlos, Y las mulas no durmieron--: los arrieros en Costa Rica, Siglos XVI al XIX, San José, EUNED, 2005.

Moreno Cabanillas, Rocío, Cartas para Gobernar. El establecimiento de la Administración de Correos de Cartagena de Indias (1764-1769), Saarbrücken, Editorial Académica Española, 2017a.

Moreno Cabanillas, Rocío, "Cartas en pugna. Resistencias y oposiciones al proyecto de reforma del correo ultramarino en España y América en el siglo XVIII", Nuevo Mundo, Mundos Nuevos (París, 2017b), https://doi.org/10.4000/nuevomundo.71547

Moreno de Ángel, Pilar, Orlando Melo, Jorge, Useche Losada, Mariano y Sierra Restrepo, Alberto, Caminos reales de Colombia, Bogotá, Fondo FEN Colombia, 1995.

Padilla Pinedo, Wilfredo, "La historia de una ciudad contada por sus calles", El informador, 29 de julio de 2016. http://www.elinformador.com.co/index.php/general/164-informe-especial/130816-la-historia-de-una-ciudad-contada-por-sus-calles

Peñas Galindo, David Ernesto, "Por las llanuras del Caribe”, Pilar Moreno de Ángel, Jorge Orlando Melo y Mariano Useche Losada (eds.), Caminos reales de Colombia, Bogotá, Fondo FEN Colombia, 1995: 99-112.

Pita Pica, Roger, "Amenazas a la fidelidad, seguridad y confianza real: el servicio de correo interno en el Nuevo Reino de Granada tras las reformas de Pando, 17641810", Memoria y sociedad, 20/40 (Bogotá, 2016): 223-241. 
Sellers-García, Sylvia, Distance and Documents at the Spanish Empire's Periphery, Stanford, Stanford University Press, 2014.

Serrera, Ramón María, Tráfico terrestre y red vial en las Indias españolas, Barcelona, Lunwerg, 1992.

Stangl, Werner, "Scylla and charybdis 2.0: reconstructing colonial Spanish American territories between metropolitan dream and effective control, historical ambiguities and cybernetic determinism", Culture \& History Digital Journal 4/2 (Madrid, 2015): e008. https://doi.org/10.3989/chdj.2015.008

Stangl, Werner, “¿Provincias y partidos o gobiernos y corregimientos? Los principios rectores del desordenamiento territorial de las Indias y la creación de un sistema de información histórico-geográfico", Jahrbuch für Geschichte Lateinamerikas/ Anuario de Historia de América Latina, 54 (Hamburgo, 2017): 157-210.

Stangl, Werner, "“The Empire Strikes Back'?: HGIS de las Indias and the Postcolonial Death Star", International Journal of Humanities and Arts Computing, 12/2 (Edimburgo, 2018): 138-162. https://doi.org/10.3366/ijhac.2018.0219

Strassnig, Christian, "Rediscovering the Camino Real of Panama: Archaeology and Heritage Tourism Potentials", Journal of Latin American Geography, 9/2 (Austin, 2010): 159-168. https://doi.org/10.1353/lag.2010.0012

Torre Revelo, José, "Descripción de rutas, caminos y autoridades de la época. Incluye un mapa de las estafetas y postas de la parte septentrional del Río de la Plata", Uruguay filatélico, 4 a época, 2 (Montevideo, 1984): 13-18.

Tovar Pinzón, Hermes, Convocatoria al poder del número. Censos y Estadísticas de la Nueva Granada, 1750-1830, Bogotá, 1994.

Viloria De la Hoz, Joaquín, 'Santa Marta Real: los 'mamatoqueros' y la 'catalanada' como defensores del régimen colonial en Santa Marta, 1810-1830", Aguaita. Revista del Observatorio del Caribe Colombiano, 26 (Cartagena de Indias, 2014): 14-24.

Fecha de recepción: 3 de enero de 2018.

Fecha de envío de las modificaciones: 8 de febrero de 2018 .

Fecha de aceptación: 8 de mayo de 2018. 


\section{The land mail of Cartagena de Indias during the Royal Administration (1768-1810). Itineraries, cartography, a "map in the form of a treatise", GPS and a GIS}

Seeking to reconstruct the spatial organization of land mail in the area of the General Administration of Cartagena de Indias, created in 1768, this article is essentially based on two manuscripts, one by José Antonio de Pando (ca. 1774) and an anonymous one from 1801 (probably by Antonio de Miranda). Both documents contain valuable information on frequency of routes, transit locations, distances between them and the quality of roads. Using complementary information such as modern roads, GPS data and georeferenced old maps, the routes are reconstructed in a Geographic Information System (GIS) in a process that at the same time allows us to ponder contemporary practices of measuring and expressing distances.

Key words: mail routes; Cartagena; Panama; Miranda; Pando; distances. 